Article

\title{
Synthesis, Characterization and Anti-Cancer Activity of Hydrazide Derivatives Incorporating a Quinoline Moiety
}

\author{
Murat Bingul 1,2, Owen Tan ${ }^{2}$, Christopher R. Gardner ${ }^{1,2}$, Selina K. Sutton ${ }^{2}$, Greg M. Arndt ${ }^{2,3}$, \\ Glenn M. Marshall ${ }^{2,4}$, Belamy B. Cheung ${ }^{2, *}$, Naresh Kumar ${ }^{1, *}$ and David StC. Black ${ }^{1, *}$ \\ 1 School of Chemistry, The University of New South Wales Australia, Sydney, NSW 2052, Australia; \\ muratbingul1983@gmail.com (M.B.); z3217087@gmail.com (C.R.G.) \\ 2 Children's Cancer Institute Australia for Medical Research, Lowy Cancer Research Centre, \\ The University of New South Wales Australia, Sydney, NSW 2031, Australia; Otan@ccia.unsw.edu.au (O.T.); \\ ssutton@ccia.unsw.edu.au (S.K.S.); garndt@ccia.unsw.edu.au (G.M.A.); \\ gmarshall@ccia.unsw.edu.au (G.M.M.) \\ 3 ACRF Drug Discovery Centre for Childhood Cancer, Children's Cancer Institute Australia for Medical \\ Research, Lowy Cancer Research Centre, The University of New South Wales Australia, Sydney, \\ NSW 2052, Australia \\ 4 Kids Cancer Centre, Sydney Children's Hospital, Randwick, NSW 2031, Australia \\ * Correspondence: bcheung@ccia.unsw.edu.au (B.B.C.); n.kumar@unsw.edu.au (N.K.); \\ d.black@unsw.edu.au (D.StC.B.); Tel.: +61-2-9385-2450 (B.B.C.); +61-2-9385-4698 (N.K.); \\ +61-2-9385-4657 (D.StC.B.)
}

Academic Editor: Jean Jacques Vanden Eynde

Received: 24 May 2016; Accepted: 8 July 2016; Published: 14 July 2016

\begin{abstract}
Identification of the novel (E)-N'-((2-chloro-7-methoxyquinolin-3-yl)methylene)-3-(phenylthio) propanehydrazide scaffold $\mathbf{1 8}$ has led to the development of a new series of biologically active hydrazide compounds. The parent compound 18 and new quinoline derivatives 19-26 were prepared from the corresponding quinoline hydrazones and substituted carboxylic acids using EDC-mediated peptide coupling reactions. Further modification of the parent compound $\mathbf{1 8}$ was achieved by replacement of the quinoline moiety with other aromatic systems. All the newly synthesized compounds were evaluated for their anti-cancer activity against the SH-SY5Y and Kelly neuroblastoma cell lines, as well as the MDA-MB-231 and MCF-7 breast adenocarcinoma cell lines. Analogues 19 and 22 significantly reduced the cell viability of neuroblastoma cancer cells with micromolar potency and significant selectivity over normal cells. The quinoline hydrazide 22 also induced $\mathrm{G}_{1}$ cell cycle arrest, as well as upregulation of the p27kip1 cell cycle regulating protein.
\end{abstract}

Keywords: quinoline; hydrazide-hydrazone; anticancer; neuroblastoma; breast cancer

\section{Introduction}

Cancer is a heterogeneous type of genetic diseases, resulting from the alteration of many key genetic and molecular pathways [1]. Treatment regimens are often harsh, with conventional chemotherapies often not being effective, also inducing side-effects and encountering drug-resistance [2]. An important class of chemotherapeutics that effectively induce cell death, but can become ineffective due to drug-resistance, are the histone deacetylase inhibitors (HDACi) [3]. These molecules exert efficacy by regulating transcription of genes that suppress cell proliferation and angiogenesis, induce cell differentiation and promote apoptosis [4,5]. In particular, the HDACi suberoylanilide hydroxamic acid (SAHA, Figure 1) has shown potent cytotoxic effects towards a number of tumour types with low toxicity towards normal cells [6,7]. As SAHA targets only a few 
signalling pathways, single agent treatment with SAHA has been found to be ineffective against several cancers $[8,9]$. Cytotoxic drugs are found to be most effective when given in combination to achieve additive or synergistic effects. The combination of SAHA with other chemotherapeutic agents that possess different mechanisms of action has been considered to be a more promising approach to reduce drug resistance and minimize overlapping toxicities $[8,10]$.<smiles>O=C(CCCCCCC(=O)Nc1ccccc1)NO</smiles>

Figure 1. Structure of the HDACi suberoylanilide hydroxamic acid (SAHA).

In order to provide a basis for the discovery of novel SAHA enhancers, a subset $(10,560$ compounds) of the Walter \& Eliza Hall Institute (WEHI) compound library was screened to identify molecules that can act synergistically with a clinical dose of SAHA to overcome resistance in SAHA-resistant MDA-MB-231 breast cancer cells, as previously reported [11]. From this screening, we identified the quinoline-hydrazide scaffold ( $E$ )- $N^{\prime}$-((2-chloro-7-methoxyquinolin-3-yl)methylene)3-(phenylthio)propane hydrazide (15, Figure 2) as a novel anti-cancer lead compound, which reduced the MDA-MB-231 cell viability by $<30 \%$ in the absence of SAHA, $>60 \%$ in the presence of SAHA and also displayed a differential of $>55 \%$ between these conditions.<smiles>COc1ccc2cc(/C=N/NC(=O)CCSc3ccccc3)c(Cl)nc2c1</smiles>

Figure 2. The structure of parent compound 15 from the WEHI screening.

Quinoline is a pharmacologically valuable scaffold that is prevalent in a variety of biologically active synthetic and natural compounds [12]. Throughout the 20th century, the chemistry of quinolines has been the subject of intense study and different interesting bioactivity such as antibacterial, antifungal, anti-inflammatory, antimalarial and anticancer activities [13-18]. This anticancer activity is quite broad, with quinoline derivatives having been used against many cancers, such as those of the breast, prostate, gastrointestinal tract, colon and liver [19-22]. Importantly, a number of quinoline-based anticancer drugs have also been used clinically, including camptothecin and its analogues (irinotecan and topotecan) $[23,24]$ and bosutinib (Figure 3) $[25,26]$.

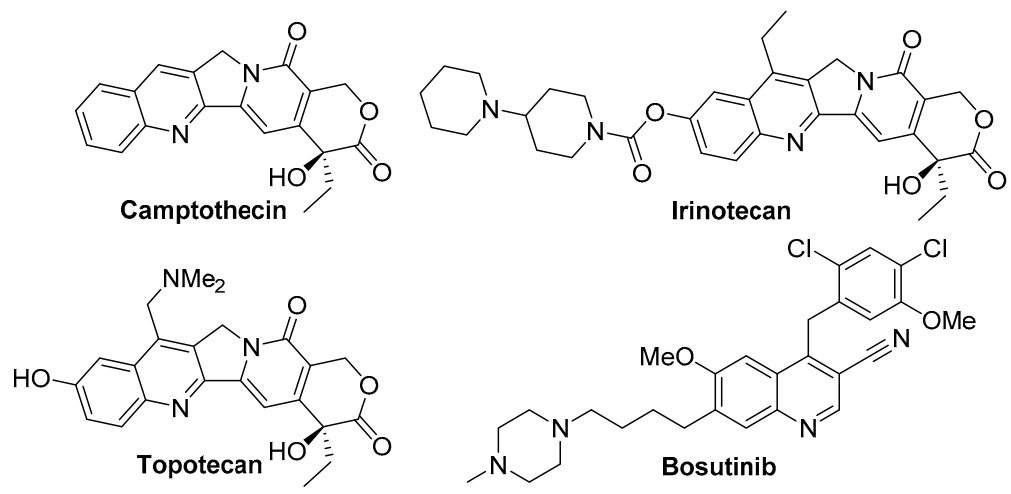

Figure 3. Structures of quinoline-containing anticancer drugs.

The hydrazide-hydrazone moiety $(-(\mathrm{C}=\mathrm{O}) \mathrm{NHN}=\mathrm{CH})$ has been identified as an important fragment for various biological activities including antibacterial, antifungal, analgesic, antiinflammatory, antidepressant and anticancer activities [27-29]. When used in conjunction with a quinoline 
system, this combination has afforded compounds with antimicrobial [30], antimycobacterial [31], anti-tubercular [32,33], anticonvulsant [34] and cytotoxic activity [35]. These biological activities are related to the many interesting and important properties of the hydrazidehydrazone moiety, such as their relatively higher metabolic stability towards proteases than amides and their tuneable, labile nature in acidic $\mathrm{pH}$. The anticancer activity of quinoline-based compounds is exerted through many mechanisms, such as apoptosis [36], inhibition of angiogenesis [37], receptor inhibition and DNA intercalation [38-41]. Many compounds also exert their activity through cell cycle arrest, particularly at the $G_{2} / M$ phase [42-45] or the $S$ phase [46-48]. However, a few examples have been reported where cell cycle arrest occurs at the $G_{0} / G_{1}$ phase $[49,50]$. p2 $7^{\text {kip1 }}$ is involved in the regulation of $G_{0}$ to $S$ phase transitions by regulating the activity of cyclin-dependent kinases [51,52]. While p27 is rarely mutated or deleted in human cancers, it is frequently deregulated through reduced expression or mislocalization to the cytoplasm [53]. Currently, p27 expression levels in cancer serve prognostic purposes [54], as they can correlate to treatment response in either a positive or inverse fashion depending upon the disease model [55-60]. However, therapeutics targeting p27 have also been investigated in numerous cancers to enforce apoptotic consequences $[61,62]$. In this paper, we report the quinoline-hydrazide (E)- $N^{\prime}$-((2-chloro-7-methoxyquinolin-3-yl)methylene)-3-(phenylthio)propane hydrazide (15, Figure 2) as a novel anticancer lead compound. We further report the synthesis, characterization and in vitro biological evaluation of a series of quinoline-based and non-quinoline-based analogues, including their effects on cell cycle distribution and the expression of the cell cycle-related p27kip1 protein.

\section{Results and Discussion}

\subsection{Synthesis of Quinoline-Based Hydrazide-Hydrazones}

In order to generate a diverse array of analogues, a convergent synthesis was envisaged, whereby the targeted hydrazide-hydrazone structure could be formed by an amide-coupling reaction between an alkyl carboxylic acid and aryl hydrazone (Scheme 1).
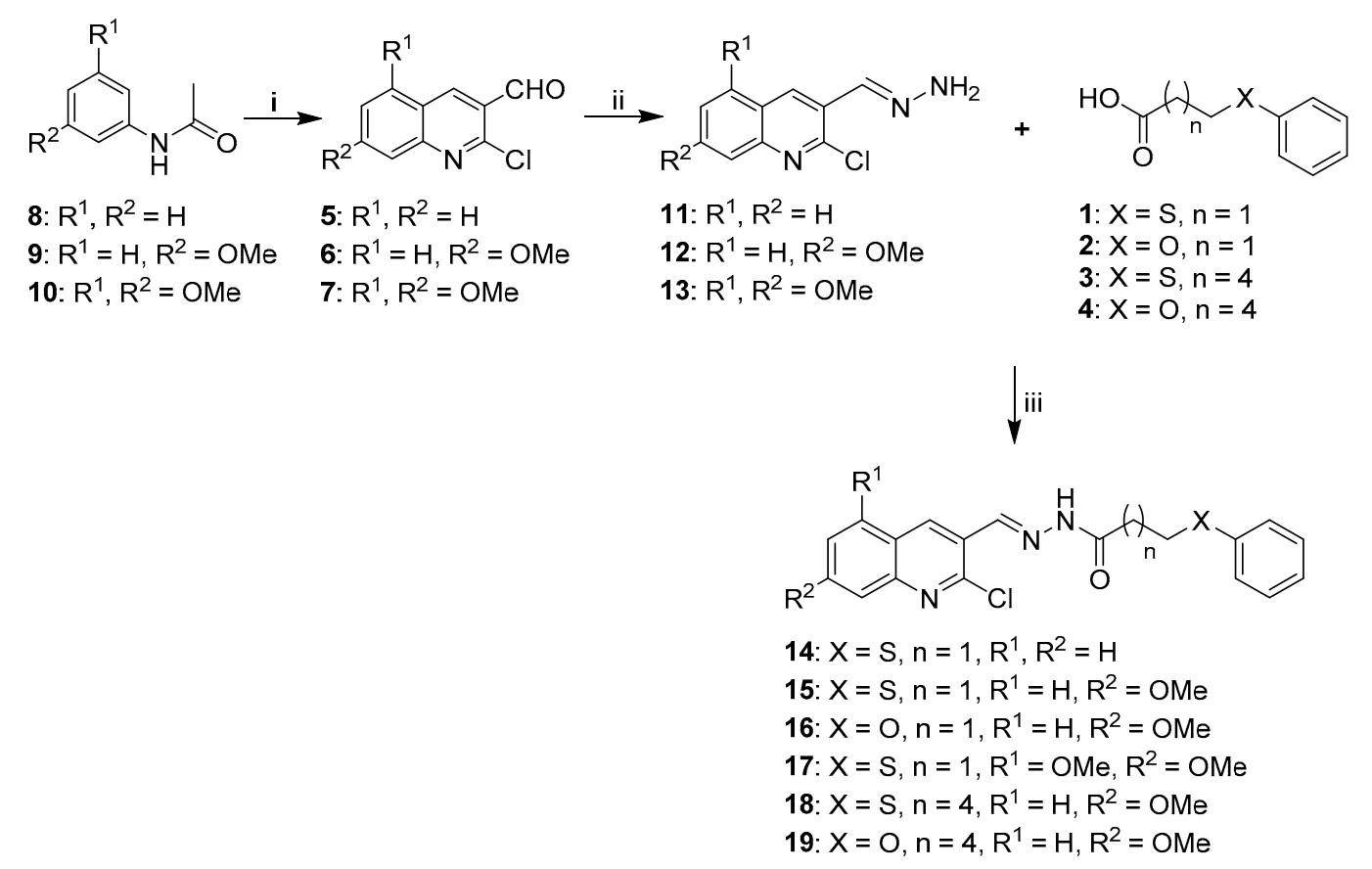

Scheme 1. Synthesis of quinoline-based hydrazide-hydrazones. Reagents and conditions: i. DMF, $\mathrm{POCl}_{3}$, $90{ }^{\circ} \mathrm{C}, 12$ h; ii. $\mathrm{NH}_{2} \mathrm{NH}_{2} \cdot \mathrm{H}_{2} \mathrm{O}, \mathrm{EtOH}, \mathrm{rt}, 18$ h. iii. EDC, DMF, Et $3 \mathrm{~N}, \mathrm{rt}, 18 \mathrm{~h}$.

The alkyl acids 1-4 were prepared following literature methods [63]. Similarly, the substituted 2-chloro- quinoline-3-carbaldehydes 5-7 were isolated in yields of $47 \%-60 \%$ following Vilsmeier 
cyclisation of the corresponding acetanilides 8-10, according to literature methods (Scheme 1) [64,65]. Following aqueous work-up, carbaldehydes 5-7 were then treated with neat hydrazine hydrate at room temperature in ethanol to generate the quinoline hydrazones 11-13 in 74\%-87\% yields (Scheme 1). Finally, the desired hydrazide-hydrazones 14-19 were obtained by EDC-coupling of the hydrazones (11-13) to the appropriate carboxylic acids 1-4 using 1-ethyl-3-(3-dimethylaminopropyl)-carbodiimide hydrochloride (EDC), which gave hydrazide-hydrazones 14-19 in yields of 62\%-68\% (Scheme 1).

\subsection{Synthesis of Non-Quinoline Hydrazide-Hydrazones}

In order to elaborate on the structure-activity relationship and identify other heterocyclic motifs with potential cytotoxic activity, the quinoline motif was replaced with naphthalene, indole and benzaldehyde. Naphthalene was selected in order to investigate the necessity of the quinoline nitrogen, which might participate in target interaction. Indole was selected not only for its known biological activities, but also to determine if the ring size is essential for activity. Benzene was selected in order to gain insight into the necessity for a system containing a pendant ring. The aldehydes 20-22 were subjected to the same synthetic protocol described above, firstly being converted to the corresponding hydrazones 23-25, followed by EDC-coupling to acid 11 to give the targeted hydrazide-hydrazones 26-28 (Scheme 2).<smiles>O=Cc1ccc2ccccc2c1</smiles>

20<smiles>O=Cc1c[nH]c2ccccc12</smiles>

22<smiles>N/N=C/c1ccc2ccccc2c1</smiles>

23

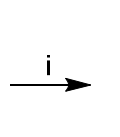<smiles>NN=Cc1c[nH]c2ccccc12</smiles>

24<smiles>N/N=C/c1ccccc1</smiles>

25<smiles>O=C(CCSc1ccccc1)N/N=C/c1ccc2ccccc2c1</smiles>

26<smiles>O=C(CCSc1ccccc1)N/N=C/c1c[nH]c2ccccc12</smiles>

28

Scheme 2. Synthesis of non-quinoline hydrazide-hydrazones. Reagents and conditions: $\mathrm{i} . \mathrm{NH}_{2} \mathrm{NH}_{2} \cdot \mathrm{H}_{2} \mathrm{O}$, EtOH, rt, 18 h; ii. 11, EDC, DMF, Et ${ }_{3} \mathrm{~N}, \mathrm{rt}, 18$ h.

The new hydrazide-hydrazones 14-19, 26-28 were characterized by physical and spectral data (IR, ${ }^{1} \mathrm{H}-\mathrm{NMR},{ }^{13} \mathrm{C}-\mathrm{NMR}$ and EIMS). The IR spectra of the derivatives showed the azomethine C-H stretching doublet absorption band at 2850-2950 $\mathrm{cm}^{-1}$, the $\mathrm{C}=\mathrm{N}$ absorption band at $1550-1600 \mathrm{~cm}^{-1}$, a carbonyl stretch at $1620-1680 \mathrm{~cm}^{-1}$ and a strong $\mathrm{N}-\mathrm{H}$ stretch at $3180-3220 \mathrm{~cm}^{-1}$. In the ${ }^{1} \mathrm{H}-\mathrm{NMR}$ spectra of the hydrazides, the azomethine proton appeared at $8.22-8.90 \mathrm{ppm}$ as a sharp singlet, whereas the corresponding amide $\mathrm{N}-\mathrm{H}$ proton appeared as a broad singlet at 9.18-9.37 ppm. The protons of the heterocyclic systems and carboxylic acid nucleus showed resonances at the expected chemical shift values.

As stereochemistry is an essential factor for biological activity, single crystals of $\mathbf{2 8}$ were examined by $\mathrm{X}$-ray diffraction in order to determine the relative stereochemistry of the $\mathrm{C}=\mathrm{N}$ bond (Figure 4). The X-ray diffraction study clearly indicated an $E$ conformation for the $\mathrm{C}=\mathrm{N}$ bond, as well as showing the alkyl chain in a bent conformation. Theoretically, this orientation might impact on the potential binding of the hydrazide-hydrazone motif to transition metals, which is a mechanism seen in multiple quinoline-hydrazone compounds [66-69]. Furthermore, it could also affect any selectivity between larger binding pockets, as opposed to shallower grooves. 


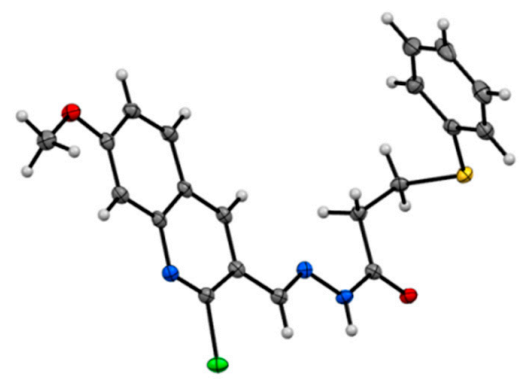

Figure 4. ORTEP diagram of X-ray crystal structure of $\mathbf{1 5}$ grown from chloroform.

\subsection{Biological Results}

\subsubsection{Cell Viability Assays}

The newly synthesized compounds were evaluated for their ability to inhibit the growth of SH-SY5Y and Kelly neuroblastoma, and MDA-MB-231 and MCF-7 breast adenocarcinoma cell lines using the Alamar blue (Resazurin) assay [70]. Briefly, the cells were allowed to attach for $24 \mathrm{~h}$ in a 96-well culture plate before being exposed to the ligands at a concentration of $10 \mu \mathrm{M}$ in DMSO for $72 \mathrm{~h}$, either in the presence or absence of SAHA. Comparative values for cell viability in each well were determined by a Wallac 1420 Victor III spectrophotometer, which measured light absorbance in each well at $570 \mathrm{~nm}$. The mean and standard deviation (SD) values for each compound were calculated from at least three replicate experiments. The anticancer activity of the compounds was evaluated by comparison to a negative (DMSO) control (Table 1 and Figure 5).

MCF-7
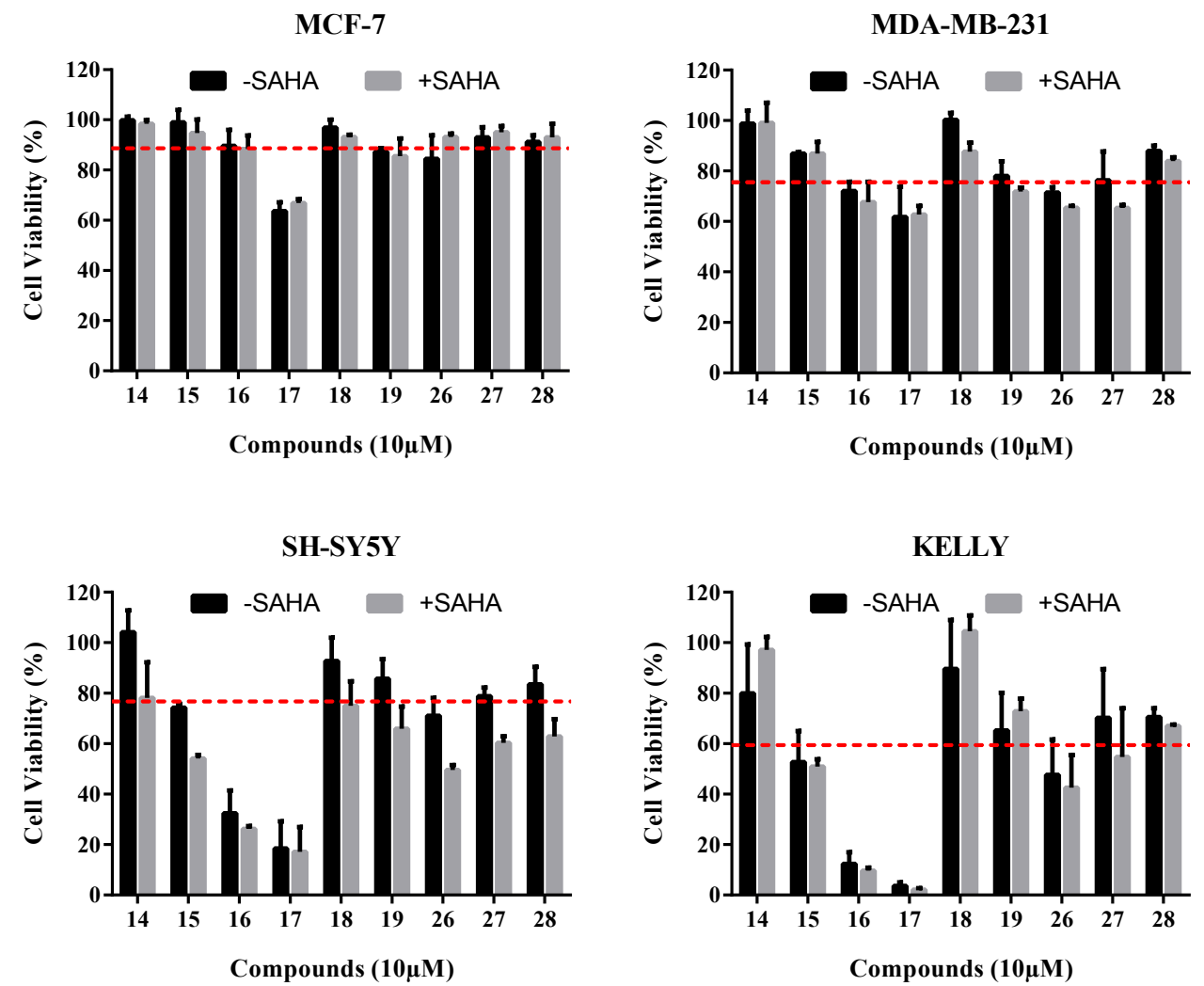

Figure 5. Cell viability of cancer cell lines after treatment at $10 \mu \mathrm{M}$ for $72 \mathrm{~h}$, given as a percentage of the negative control (DMSO). Red line represents the cell viability of cell lines after treatment with $1 \mu \mathrm{M}$ SAHA (0.5 $\mu \mathrm{M}$ SAHA for KELLY cells). Data represents the mean values ( \pm S.D.) for three independent determinations. 
Table 1. Cell viability of cancer cell lines after treatment at $10 \mu \mathrm{M}$ for $72 \mathrm{~h}$, given as a percentage of the negative control (DMSO). Data represents the mean values ( \pm S.D.) for three independent determinations.

\begin{tabular}{ccccc}
\hline \multirow{2}{*}{ Compound } & \multicolumn{4}{c}{ Cell Viability (\% of Negative Control) } \\
\cline { 2 - 5 } & MCF-7 & MDA-MB-231 & SH-SY5Y & Kelly \\
\hline $\mathbf{1 4}$ & $98.5 \pm 1.0$ & $93.8 \pm 3.6$ & $104.2 \pm 6.2$ & $80.0 \pm 13.7$ \\
$\mathbf{1 5}$ & $94.8 \pm 3.8$ & $86.9 \pm 0.5$ & $74.3 \pm 1.0$ & $52.7 \pm 8.7$ \\
$\mathbf{1 6}$ & $88.4 \pm 3.8$ & $72.0 \pm 2.6$ & $32.4 \pm 6.4$ & $12.4 \pm 3.2$ \\
$\mathbf{1 7}$ & $66.8 \pm 1.2$ & $61.8 \pm 8.4$ & $18.4 \pm 7.0$ & $3.7 \pm 1.0$ \\
$\mathbf{1 8}$ & $93.1 \pm 0.6$ & $100.2 \pm 2.0$ & $92.8 \pm 6.6$ & $89.7 \pm 13.7$ \\
$\mathbf{1 9}$ & $85.6 \pm 4.9$ & $78.0 \pm 4.1$ & $85.8 \pm 5.5$ & $65.2 \pm 10.5$ \\
$\mathbf{2 6}$ & $93.1 \pm 1.0$ & $71.5 \pm 1.5$ & $71.0 \pm 5.0$ & $47.6 \pm 9.9$ \\
$\mathbf{2 7}$ & $95.1 \pm 1.7$ & $76.4 \pm 8.0$ & $78.8 \pm 2.5$ & $70.2 \pm 13.7$ \\
$\mathbf{2 8}$ & $93.1 \pm 3.8$ & $87.9 \pm 1.5$ & $83.6 \pm 4.9$ & $70.6 \pm 2.4$ \\
\hline
\end{tabular}

In general, it was found that these compounds displayed similar levels of activity whether in the presence or absence of SAHA. It was also observed that the hydrazide-hydrazone compounds had a greater cytotoxic effect on the neuroblastoma cells (SH-SY5Y and Kelly) compared to the breast cancer cell lines (MCF-7 and MDA-MB-231). MCF-7 cells were found to be the most resistant towards treatment with the hydrazide compounds, with reductions in cell viability ranging from $5 \%-33 \%$. The compounds were generally more effective in the MDA-MB-231 breast adenocarcinoma cell line, with cell viability values being up to $20 \%$ lower than those in the MCF-7 cell line. Similarly, these compounds were also observed to have a greater effect on the cell viability of the Kelly neuroblastoma cell line than the SH-SY5Y cell line, again with up to $20 \%$ lower cell viability.

Notably, compound 17, bearing an additional methoxy group, was found to be the most active agent against both breast adenocarcinoma cell lines, with cell reductions of $33 \%$ and $38 \%$ in MCF-7 and MDA-MB-231 cells, respectively. Further, this compound was also the most active agent against the neuroblastoma cell lines, with reductions in cell viability of $82 \%$ and $96 \%$ in the SH-SY5Y and Kelly cell lines, respectively. The importance of the methoxy groups was further demonstrated by the observation that compound 14, which bears no methoxy substituents, had lower activity than the lead compound $\mathbf{1 5}$. While compound $\mathbf{1 4}$ showed no activity towards breast adenocarcinoma cell lines, the highest activity was observed with the $20 \%$ reduction in cell viability of Kelly cells.

It was also found that replacing the sulfane linkage with an ether linkage increased the potency of the synthesized compounds. The ether 16, which was found to be the second most active compound of those screened, displayed an enhanced potency of $42 \%$ and $40 \%$ against the SH-SY5Y and Kelly cell lines, respectively, compared to the corresponding sulfane lead compound $\mathbf{1 5}$. However, only $15 \%$ and $6 \%$ of additional reductions were observed for the MDA-MB-231 and MCF-7 cell lines respectively. The ether 19 showed 7\% and 25\% greater reductions in cell viability towards the SH-SY5Y and Kelly cell lines, respectively, than was observed for the corresponding sulfane 18 . Similarly, $7 \%$ and $22 \%$ of additional reductions were observed for the MCF-7 and MDA-MB-231 cell lines respectively.

Hydrazides with shorter chains were also found to be more potent than their longer chain counterparts. With respect to compounds $15(n=1)$ and $18(n=4)$, bearing sulfane linkages, it was observed that compound 15 reduced viability of Kelly cells by up to $37 \%$ more than compound 18 . In the case of SH-SY5Y cell, 18\% of additional reduction was observed. Similarly, the shorter chain analogue $\mathbf{1 6}$ reduced cell viability by up to $53 \%$ more than its longer chain analogue 19 for both Kelly and SH-SY5Y neuroblastoma cell lines.

Additionally, the replacement of the quinoline system with other aromatic groups generally led to a reduction in activity. Replacement of the quinoline (compound 15) with naphthalene (compound 26) resulted in similar levels of cytotoxicity across all cell lines and exhibited up to a $54 \%$ of reduction in the case of Kelly cells. MCF-7 was found to be the most resistant cell with only $7 \%$ reduction. However, the indole (compound 27) and phenyl (compound 28) derivatives showed significant decrease in 
activity compared to $\mathbf{1 5}$, with 28 typically having lower activity than $\mathbf{2 7}$. This suggests that the size of this heterocycle is important for its cytotoxic activity, with bicyclic systems more favourable than the tested monocyclic counterpart.

Dose response experiments were also conducted for the most potent compounds $\mathbf{1 6}$ and 17. These compounds were tested against the neuroblastoma and breast adenocarcinoma cell lines at concentrations ranging from $0.1-25.0 \mu \mathrm{M}$, with their $\mathrm{IC}_{50}$ values determined (Table 2). Compound 16 showed $\mathrm{IC}_{50}$ values of 5.7 and $2.4 \mu \mathrm{M}$ against SH-SY5Y and Kelly neuroblastoma cells, respectively, with the $\mathrm{IC}_{50}$ value against the MCF-7 breast adenocarcinoma cell line greater than the maximum tested dosage. On the other hand, the most active compound 17, showed $\mathrm{IC}_{50}$ values of 2.9 and $1.3 \mu \mathrm{M}$ against the SH-SY5Y and Kelly cells, respectively, and values of 14.1 and $18.8 \mu \mathrm{M}$ for MCF-7 and MDA-MB-231 breast cancer cells, respectively.

Table 2. $\mathrm{IC}_{50}$ values of compounds 16 and 17 against four different cancer cell lines.

\begin{tabular}{ccccc}
\hline \multirow{2}{*}{ Compound } & \multicolumn{4}{c}{ IC $_{\mathbf{5 0}}(\mu \mathrm{M})^{\mathbf{a}}$} \\
\cline { 2 - 5 } & MCF-7 & MDA-MB-231 & SH-SY5Y & Kelly \\
\hline $\mathbf{1 6}$ & $>25.0$ & 22.1 & 5.7 & 2.4 \\
$\mathbf{1 7}$ & 14.1 & 18.8 & 2.9 & 1.3
\end{tabular}

a Compound concentration required to reduce cell viability by $50 \%$, as determined by the Alamar Blue assay, under conditions allowing untreated controls to undergo at least five consecutive rounds of multiplication.

\subsubsection{Toxicity Study on Normal Human Cells}

Compounds 16 and 17 were then further tested against the MRC-5 and WI-38 normal human lung fibroblast cell lines (Figure 6). At a concentration of $10 \mu \mathrm{M}, 16$ reduced MRC-5 and WI-38 cell viability by only $10 \%$ and 5\% respectively, while 17 reduced cell viability by about $30 \%$ in the two normal lung fibroblast cell lines. Notably, these two compounds were significantly less toxic towards the normal lung fibroblast cells compared to neuroblastoma cells. Taken together, the data suggests that these novel quinoline hydrazides warrant further investigation as potential anti-cancer agents, particularly for the treatment of neuroblastoma.

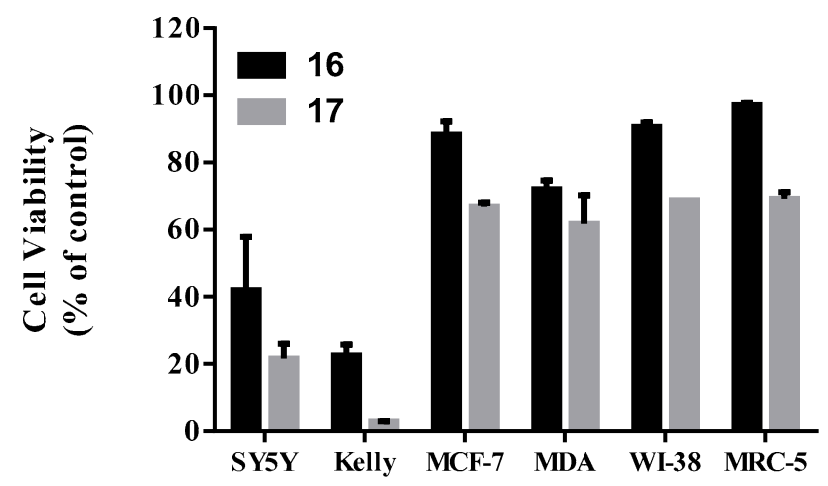

Figure 6. Comparative toxicity of compounds 29 and 30 against the tested cell lines at $10 \mu \mathrm{M}$ after $72 \mathrm{~h}$ exposure. Cell viability values are quoted as a percentage of the negative control.

\subsubsection{Effects on Cell Cycle and the Expression of Related Proteins}

In order to determine if the synthesized compounds $\mathbf{1 6}$ and $\mathbf{1 7}$ play an active role in cell cycle progression, we analysed their effect on the cell cycle progression of SH-SY5Y cells after $72 \mathrm{~h}$ treatment. It was found that cells treated with $10 \mu \mathrm{M}$ of compound 16 showed no significant difference in the proportions of cells across the cell cycle, compared to the DMSO control (Figure 7). Interestingly, cells treated with $10 \mu \mathrm{M}$ of compound 17 showed an increased proportion of cells in $\mathrm{G}_{0} / \mathrm{G}_{1}$, with $69 \%$ of cells in $G_{0} / G_{1}$, compared with the solvent control treated cells with $61 \%$ of cells in $G_{0} / G_{1}$ 
(Figure 7). Furthermore, treatment with compound 17 also reduced the number of cells in the $S$ phase and $\mathrm{G}_{2} / \mathrm{M}$ phase.

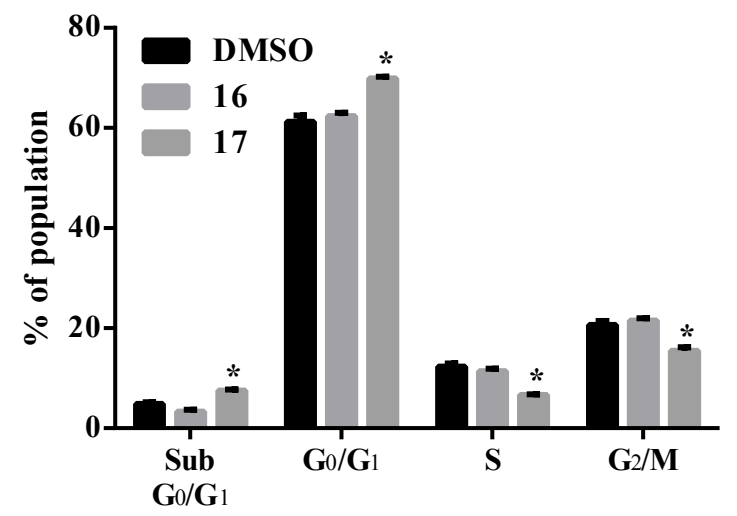

Figure 7. Comparative cell cycle distribution of SH-SY5Y cells after $72 \mathrm{~h}$ exposure to $10 \mu \mathrm{M}$ of compounds 16 and $17 .{ }^{*} p<0.05$.

To further investigate their mechanism of action on the cell cycle, immunoblot analysis was performed on proteins harvested from SH-SY5Y cells treated with compounds $\mathbf{1 6}$ and $\mathbf{1 7}$. No changes were observed in the levels $\mathrm{E} 2 \mathrm{~F} 1, \mathrm{pRb}$ and $\mathrm{p} 27^{\mathrm{kip} 1}$ protein expression, in comparison to the negative control, following $72 \mathrm{~h}$ treatment with $10 \mu \mathrm{M}$ of $\mathbf{1 6}$ (Figure 8).

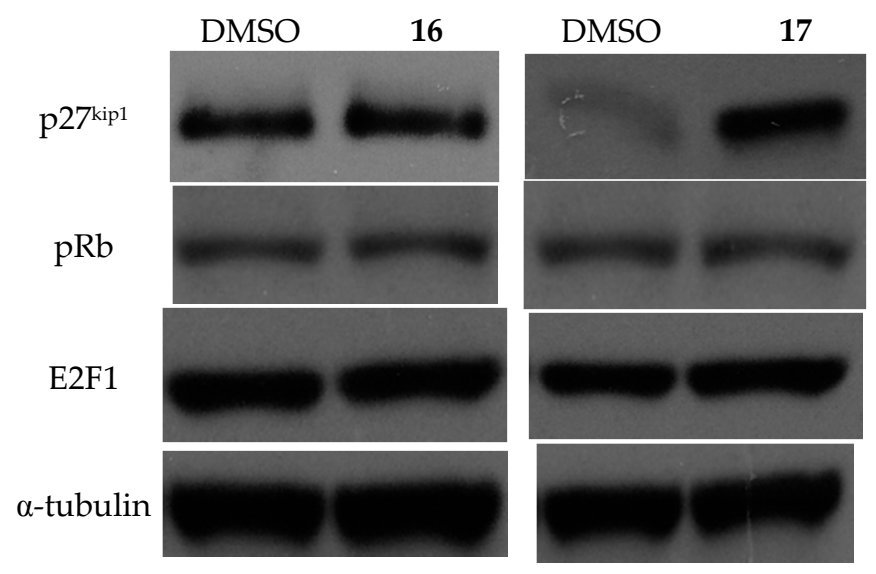

Figure 8. Immunoblot analysis of $\mathrm{p} 27^{\mathrm{kip} 1}$ and E2F1 proteins isolated from SH-SY5Y cells treated with $10 \mu \mathrm{M}$ of compounds $\mathbf{1 6}$ and $\mathbf{1 7}$ over $72 \mathrm{~h}$. Anti- $\alpha$-tubulin antibody was used for the loading control.

On the other hand, p27kip1 was highly up-regulated in SH-SY5Y cells treated with $10 \mu \mathrm{M}$ of compound 17, in comparison with the solvent control (Figure 8). However, two other cell cycle regulatory proteins, E2F1 and pRb, were unchanged by treatment with compound 17 . Since p $27^{\mathrm{kip} 1}$ is a protein that prevents cell progression from the $G_{1}$ to $S$ phase, the results suggest that compound $\mathbf{1 7}$ induces cell cycle arrest by up-regulating p2 ${ }^{\text {kip1 }}$.

\section{Materials and Methods}

\subsection{General Information}

Commercially available reagents were purchased from Fluka (Sydney, NSW, Australia), Aldrich (Sydney, NSW, Australia), Acros Organics (Morris Plains, NJ, USA), Alfa Aesar (Lancashire, UK) and Lancaster (Lancashire, UK) and purified if necessary. The synthetic procedures have been reported for all compounds as general methods and appropriate references have been given for known compounds. 
${ }^{1} \mathrm{H}(300 \mathrm{MHz})$ and ${ }^{13} \mathrm{C}-\mathrm{NMR}(75 \mathrm{MHz})$ spectra were obtained in the designated solvents on a DPX 300 spectrometer (Bruker, Sydney, NSW, Australia). Melting points were measured using a Mel-Temp melting point apparatus and are uncorrected. Infrared spectra were recorded on a Avatar Series FTIR spectrophotometer as KBr disks (Thermo Nicolet, Waltham, MA, USA). Ultraviolet spectra were measured using a Cary 100 spectrophotometer (Varian, Santa Clara, CA, USA) in the designated solvents and data reported as wavelength $(\lambda)$ in $\mathrm{nm}$ and adsorption coefficient $(\varepsilon)$ in $\mathrm{cm}^{-1} \mathrm{M}^{-1}$. High-resolution [ESI] mass spectra were recorded by the UNSW Bioanalytical Mass Spectrometry Facility, on an Orbitrap LTQ XL (Thermo Scientific, Waltham, MA, USA) ion trap mass spectrometer using a nanospray (nano-electrospray) ionization source.

\subsubsection{General Procedure for the Synthesis of Substituted Carboxylic Acids 1-4}

To a solution of thiophenol or phenol $(10 \mathrm{mmol})$ in aqueous $10 \% \mathrm{KOH}(25 \mathrm{~mL})$ and $\mathrm{EtOH}$ $(30 \mathrm{~mL})$ was added 3-bromopropionic acid or 6-bromohexanoic acid $(11 \mathrm{mmol})$ in a saturated solution of $\mathrm{K}_{2} \mathrm{CO}_{3}(10 \mathrm{~mL}, 5.5 \mathrm{mmol})$. The resulting mixture was heated at reflux for $5 \mathrm{~h}$. The reaction mixture was neutralized with $18 \% \mathrm{HCl}$ solution and the resulting precipitate was collected via filtration, washed with water and crystallized from petroleum ether to give the product as a white solid.

3-(Phenylthio)propanoic acid (1) [63]. White solid, yield: 88\%; m.p. 59-60 ${ }^{\circ} \mathrm{C}$ (lit. [63] m.p. 58-59 ${ }^{\circ} \mathrm{C}$ ); ${ }^{1} \mathrm{H}-\mathrm{NMR}\left(\mathrm{CDCl}_{3}\right): \delta 7.41-7.33(4 \mathrm{H}, \mathrm{m}, \mathrm{ArH}), 7.27-7.22(1 \mathrm{H}, \mathrm{m}, \mathrm{ArH}), 3.22\left(2 \mathrm{H}, \mathrm{t}, J=7.2 \mathrm{~Hz}, \mathrm{CH}_{2}\right), 2.65$ $\left(2 \mathrm{H}, \mathrm{t}, J=7.2 \mathrm{~Hz}, \mathrm{CH}_{2}\right)$.

3-Phenoxypropanoic acid (2) [71]. White solid, yield: 85\%; m.p. 92-94 ${ }^{\circ} \mathrm{C}$ (lit. [71] m.p. $95-96{ }^{\circ} \mathrm{C}$ ); ${ }^{1} \mathrm{H}-\mathrm{NMR}\left(\mathrm{CDCl}_{3}\right): \delta 7.34-7.29(4 \mathrm{H}, \mathrm{m}, \mathrm{ArH}), 7.01-6.92(1 \mathrm{H}, \mathrm{m}, \mathrm{ArH}), 4.29\left(2 \mathrm{H}, \mathrm{t}, J=6.3 \mathrm{~Hz}, \mathrm{CH}_{2}\right), 2.88$ $\left(2 \mathrm{H}, \mathrm{t}, J=6.3 \mathrm{~Hz}, \mathrm{CH}_{2}\right)$.

6-(Phenylthio)hexanoic acid (3) [72]. White crystals, yield: 95\%; m.p. $62-63^{\circ} \mathrm{C}$ (lit. [72] m.p. not given); ${ }^{1} \mathrm{H}-\mathrm{NMR}\left(\mathrm{CDCl}_{3}\right): \delta 7.31-7.26(2 \mathrm{H}, \mathrm{m}, \mathrm{ArH}), 6.96-6.90(3 \mathrm{H}, \mathrm{m}, \mathrm{ArH}), 4.02\left(2 \mathrm{H}, \mathrm{t}, J=7.2 \mathrm{~Hz}, \mathrm{CH}_{2}\right), 2.36$ $\left(2 \mathrm{H}, \mathrm{t}, J=7.5 \mathrm{~Hz}, \mathrm{CH}_{2}\right), 1.87-1.65\left(4 \mathrm{H}, \mathrm{m}, \mathrm{CH}_{2}-\mathrm{CH}_{2}\right), 1.61-1.50\left(2 \mathrm{H}, \mathrm{m}, \mathrm{CH}_{2}\right)$.

6-Phenoxyhexanoic acid (4) [72]. White crystals, yield: 89\%; m.p. $66-68{ }^{\circ} \mathrm{C}$ (lit. [72] m.p. not given); ${ }^{1} \mathrm{H}-\mathrm{NMR}\left(\mathrm{CDCl}_{3}\right): \delta 7.38-7.35(3 \mathrm{H}, \mathrm{m}, \mathrm{ArH}), 7.30-717(2 \mathrm{H}, \mathrm{m}, \mathrm{ArH}), 3.00\left(2 \mathrm{H}, \mathrm{t}, J=6.4 \mathrm{~Hz}, \mathrm{CH}_{2}\right), 2.32$ $\left(2 \mathrm{H}, \mathrm{t}, J=6.2 \mathrm{~Hz}, \mathrm{CH}_{2}\right), 1.69-1.60\left(4 \mathrm{H}, \mathrm{m}, \mathrm{CH}_{2}-\mathrm{CH}_{2}\right), 1.57-1.46\left(2 \mathrm{H}, \mathrm{m}, \mathrm{CH}_{2}\right)$.

\subsubsection{General Procedure for the Synthesis of Acetylated Anilines 8-10}

A mixture of the appropriate aniline $(50 \mathrm{mmol})$ and dimethoxyaminopyridine (DMAP, $50 \mathrm{mmol}$ ) in dichloromethane $(100 \mathrm{~mL})$ was stirred for $10 \mathrm{~min}$ at room temperature. Acetic anhydride (50 mmol) was added dropwise and the resulting mixture was stirred for a further $4 \mathrm{~h}$ at room temperature. Water $(25 \mathrm{~mL})$ was added and the resulting precipitate was thoroughly washed with ethanol followed by water to remove unreacted acetic anhydride and acetic acid. The desired product was dried at $50{ }^{\circ} \mathrm{C}$ under vacuum to yield the acetyl derivatives as a white solid.

N-Phenylacetamide (8) [73]. White solid, yield: $94 \%$; m.p. $112-114{ }^{\circ} \mathrm{C}$ (lit. [73] m.p. $113-115{ }^{\circ} \mathrm{C}$ ); ${ }^{1} \mathrm{H}-\mathrm{NMR}\left(\mathrm{CDCl}_{3}\right): \delta 7.49(2 \mathrm{H}, \mathrm{t}, J=4.4 \mathrm{~Hz}, \mathrm{H} 2$ and $\mathrm{H} 6), 7.37(1 \mathrm{H}, \mathrm{bs} \mathrm{NH}), 7.34(2 \mathrm{H}, \mathrm{t}, J=8.0 \mathrm{~Hz}, \mathrm{H} 3$ and $\mathrm{H} 5), 7.13(1 \mathrm{H}, \mathrm{t}, J=7.4 \mathrm{~Hz}, \mathrm{H} 4), 2.20\left(3 \mathrm{H}, \mathrm{s}, \mathrm{CH}_{3}\right)$.

$\mathrm{N}$-(3-Methoxyphenyl)acetamide (9) [74]. White solid, yield: 88\%; m.p. $80-82{ }^{\circ} \mathrm{C}$ (lit. [74] m.p. 81-83 ${ }^{\circ} \mathrm{C}$ ); ${ }^{1} \mathrm{H}-\mathrm{NMR}\left(\mathrm{CDCl}_{3}\right): \delta 7.45(1 \mathrm{H}, \mathrm{bs}, \mathrm{NH}), 7.30-7.23(2 \mathrm{H}, \mathrm{m}, \mathrm{H} 4-\mathrm{H} 5), 6.99(1 \mathrm{H}, \mathrm{d}, J=8.0 \mathrm{~Hz}, \mathrm{H} 2), 6.69(1 \mathrm{H}$, $\mathrm{dd}, J=2.1,8.1 \mathrm{~Hz}, \mathrm{H} 6), 3.82(3 \mathrm{H}, \mathrm{s}, \mathrm{OMe}), 2.20\left(3 \mathrm{H}, \mathrm{s}, \mathrm{CH}_{3}\right)$.

N-(3,5-Dimethoxyphenyl)acetamide (10) [75]. White solid, yield: 90\%; m.p. 152-154 ${ }^{\circ} \mathrm{C}$ (lit. [75] m.p. not given); ${ }^{1} \mathrm{H}-\mathrm{NMR}\left(\mathrm{CDCl}_{3}\right): \delta 7.53(1 \mathrm{H}, \mathrm{bs}, \mathrm{NH}), 6.78(2 \mathrm{H}, \mathrm{d}, J=2.34 \mathrm{~Hz}, \mathrm{H} 2$ and $\mathrm{H} 4), 6.27(1 \mathrm{H}, \mathrm{t}$, $J=2.34 \mathrm{~Hz}, \mathrm{H} 6), 3.80(6 \mathrm{H}, \mathrm{s}, 2 \times \mathrm{OMe}), 2.20\left(3 \mathrm{H}, \mathrm{s}, \mathrm{CH}_{3}\right)$. 
3.1.3. General Procedure for the Synthesis of 2-Chloro-3-Formylquinolines (5-7).

$\mathrm{N}, \mathrm{N}$-Dimethylformamide $(0.025 \mathrm{~mol})$ was cooled in an ice-salt bath and treated with phosphoryl chloride $(0.070 \mathrm{~mol})$ for $20 \mathrm{~min}$. The resulting mixture was added dropwise to a cooled solution of the appropriate acetylated aniline (8-10) $(0.010 \mathrm{~mol})$ in $\mathrm{N}, \mathrm{N}$-dimethylformamide $(10 \mathrm{~mL})$ with stirring. The mixture was stirred at $90^{\circ} \mathrm{C}$ for $12 \mathrm{~h}$. A small amount of crushed ice was added and the mixture was basified to $\mathrm{pH} 14$ with $5 \mathrm{M} \mathrm{NaOH}$. After stirring at ambient temperature for $1 \mathrm{~h}$, the precipitate was filtered, washed with water, and dried to give the title compound.

2-Chloroquinoline-3-carbaldehyde (5) [76]. Yellow solid, yield: 60\%; m.p. $150-152{ }^{\circ} \mathrm{C}$ (lit. [76] m.p. 146-149 $\left.{ }^{\circ} \mathrm{C}\right) ;{ }^{1} \mathrm{H}-\mathrm{NMR}\left(\mathrm{CDCl}_{3}\right): \delta 10.59(1 \mathrm{H}, \mathrm{s}, \mathrm{CHO}), 8.79(1 \mathrm{H}, \mathrm{s}, \mathrm{H} 4), 8.11-7.65(4 \mathrm{H}, \mathrm{m}, \mathrm{H} 5, \mathrm{H} 6$, $\mathrm{H} 7, \mathrm{H} 8)$.

2-Chloro-7-methoxyquinoline-3-carbaldehyde (6) [64]. Yellow solid, yield: 55\%; m.p. 195-197 ${ }^{\circ} \mathrm{C}$ (lit. [64] m.p. $\left.196-197^{\circ} \mathrm{C}\right) ;{ }^{1} \mathrm{H}-\mathrm{NMR}\left(\mathrm{CDCl}_{3}\right): \delta 10.54(1 \mathrm{H}, \mathrm{s}, \mathrm{CHO}), 8.70(1 \mathrm{H}, \mathrm{s}, \mathrm{H} 4), 7.89(1 \mathrm{H}, \mathrm{d}, J=9.0 \mathrm{~Hz}, \mathrm{H} 5)$, $7.42(1 \mathrm{H}, \mathrm{d}, J=2.5 \mathrm{~Hz}, \mathrm{H} 8), 7.32(1 \mathrm{H}, \mathrm{dd}, J=2.5,9.0 \mathrm{~Hz}, \mathrm{H} 6) 4.00(3 \mathrm{H}, \mathrm{s}, \mathrm{OMe})$.

2-Chloro-5,7-dimethoxyquinoline-3-carbaldehyde (7). Yellow solid, yield: 47\%; m.p. $160-162{ }^{\circ} \mathrm{C}$; UV-vis (MeOH): $\lambda_{\max } 314 \mathrm{~nm}\left(\varepsilon 7,100 \mathrm{~cm}^{-1} \mathrm{M}^{-1}\right), 347(9,500) ;{ }^{1} \mathrm{H}-\mathrm{NMR}\left(\mathrm{CDCl}_{3}\right): \delta 11.18(1 \mathrm{H}, \mathrm{s}, \mathrm{CHO}), 8.43$ $(1 \mathrm{H}, \mathrm{d}, J=8.7 \mathrm{~Hz}, \mathrm{H} 6), 7.32(1 \mathrm{H}, \mathrm{d}, J=8.7 \mathrm{~Hz}, \mathrm{H} 8), 6.66(1 \mathrm{H}, \mathrm{s}, \mathrm{H} 4), 4.13(6 \mathrm{H}, \mathrm{s}, 2 \times \mathrm{OMe}) ;{ }^{13} \mathrm{C}-\mathrm{NMR}$ $\left(\mathrm{CDCl}_{3}\right): \delta 190.18(\mathrm{C}=\mathrm{O}), 164.21$ (C5), 160.97 (C7), 152.89 (C2), 150.39 (aryl C), 133.91 (C4), 119.99 (C3), 113.75 (aryl C), 111.16 (C6), 92.73 (C8), 106.87 (C8), 56.66 and 56.23 (OMe) HRMS (ESI): $\mathrm{C}_{12} \mathrm{H}_{10} \mathrm{ClNO}_{3}$ $[\mathrm{M}]^{+}$requires 274.0241 , found 274.0241 .

\subsubsection{General Procedure for the Preparation of Hydrazones 11-13, 23-25}

A mixture of the appropriate aldehyde 5-7, 20-22 (5 mmol) and excess hydrazine hydrate was stirred overnight in ethanol. After completion of the reaction, the solvent was evaporated. Water was added to the residue and the resulting mixture was extracted with ethyl acetate. The organic extract was dried with anhydrous sodium sulfate and the solvent was evaporated under reduced pressure to give the title compound.

(E)-2-Chloro-3-(hydrazonomethyl)quinolone (11) [77]. Yellow solid, yield: 87\%; m.p. 140-142 ${ }^{\circ} \mathrm{C}$ (lit. [77] m.p. $\left.135^{\circ} \mathrm{C}\right) ;{ }^{1} \mathrm{H}-\mathrm{NMR}\left(\mathrm{CDCl}_{3}\right): \delta 8.63(1 \mathrm{H}, \mathrm{s}, \mathrm{H} 4), 8.09-8.06(1 \mathrm{H}, \mathrm{m}, \mathrm{H} 5), 8.06(1 \mathrm{H}, \mathrm{s}, \mathrm{CH}), 7.93-7.91$ $(1 \mathrm{H}, \mathrm{m}, \mathrm{H} 8), 7.79-7.73(1 \mathrm{H}, \mathrm{m}, \mathrm{H} 6)$ 7.66-7.60 (1H, m, H7), $7.58\left(2 \mathrm{H}, \mathrm{bs}, \mathrm{NH}_{2}\right)$.

(E)-2-Chloro-3-(hydrazonomethyl)-7-methoxyquinoline (12) [77]. Yellow solid, yield: 80\%; m.p. $166-168{ }^{\circ} \mathrm{C}$ (lit. [77] m.p. $\left.165^{\circ} \mathrm{C}\right) ;{ }^{1} \mathrm{H}-\mathrm{NMR}\left(\mathrm{CDCl}_{3}\right): \delta 8.57(1 \mathrm{H}, \mathrm{s}, \mathrm{H} 4), 8.20(1 \mathrm{H}, \mathrm{s}, \mathrm{CH}), 7.74(1 \mathrm{H}, \mathrm{d}, J=9.0 \mathrm{~Hz}$, H5), $7.34(1 \mathrm{H}, \mathrm{d}, J=2.5 \mathrm{~Hz}, \mathrm{H} 8), 7.22(1 \mathrm{H}, \mathrm{dd}, J=2.5,9.0 \mathrm{~Hz}, \mathrm{H} 6) 5.86\left(2 \mathrm{H}, \mathrm{s}, \mathrm{NH}_{2}\right), 3.97(3 \mathrm{H}, \mathrm{s}, \mathrm{OMe})$.

(E)-2-Chloro-3-(hydrazonomethyl)-5,7-dimethoxyquinoline (13). Yellow solid, yield: 74\%; m.p. 198-200 ${ }^{\circ} \mathrm{C}$; IR (KBr): $v_{\max } 3403,2942,1610,1499,1466,1349,1263,1220,1175,1132 \mathrm{~cm}^{-1}$; UV-vis (MeOH): $\lambda_{\max } 315 \mathrm{~nm}\left(\varepsilon 2,800 \mathrm{~cm}^{-1} \mathrm{M}^{-1}\right), 362(4,900) ;{ }^{1} \mathrm{H}-\mathrm{NMR}\left(\mathrm{CDCl}_{3}\right): \delta 8.44(1 \mathrm{H}, \mathrm{d}, J=8.7 \mathrm{~Hz}, \mathrm{H} 6)$, $8.40(1 \mathrm{H}, \mathrm{s}, \mathrm{CH}), 7.38(1 \mathrm{H}, \mathrm{d}, J=8.7 \mathrm{~Hz}, \mathrm{H} 8), 7.02(1 \mathrm{H}, \mathrm{s}, \mathrm{H} 4), 6.63\left(2 \mathrm{H}, \mathrm{bs}, \mathrm{NH}_{2}\right), 4.08$ and 3.98 (each 3H, s, OMe). ${ }^{13} \mathrm{C}-\mathrm{NMR}\left(\mathrm{CDCl}_{3}\right): \delta 159.73(\mathrm{C} 5), 156.24(\mathrm{C} 7), 151.29(\mathrm{C} 2), 147.74(\operatorname{aryl} \mathrm{C}), 139.93(\mathrm{CH})$, 133.86 (C4), 119.17 (C3), $114.03(\operatorname{aryl} \mathrm{C}), 102.36$ (C6), 94.04 (C8), 106.87 (C8), 56.85 and 55.86 (OMe); $\mathrm{C}_{12} \mathrm{H}_{12} \mathrm{ClN}_{3} \mathrm{NaO}_{2}[\mathrm{M}+\mathrm{Na}]^{+}$requires 288.0516, found 288.0503 .

(E)-(Naphthalen-2-ylmethylene)hydrazine (23) [78]. Yellow solid, yield: 83\%; m.p. 152-154 ${ }^{\circ} \mathrm{C}$ (lit. [78] m.p. $\left.148-151{ }^{\circ} \mathrm{C}\right) ;{ }^{1} \mathrm{H}-\mathrm{NMR}\left(\mathrm{CDCl}_{3}\right): \delta 7.94(1 \mathrm{H}, \mathrm{s}, \mathrm{CH}), 7.91-7.83(5 \mathrm{H}, \mathrm{m}, \mathrm{ArH}), 7.50-7.46(2 \mathrm{H}, \mathrm{m}, \mathrm{H} 3$ and $\mathrm{H} 4), 5.63\left(2 \mathrm{H}, \mathrm{s}, \mathrm{NH}_{2}\right)$.

(E)-3-(Hydrazonomethyl)-1H-indole (24) [79]. Yellow solid, yield: 76\%; m.p. 158-160 ${ }^{\circ} \mathrm{C}$ (lit. [79] not given); ${ }^{1} \mathrm{H}-\mathrm{NMR}\left(\mathrm{CDCl}_{3}\right): \delta 11.69(1 \mathrm{H}, \mathrm{bs}, \mathrm{NH}), 8.92(1 \mathrm{H}, \mathrm{s}, \mathrm{CH}), 8.35(1 \mathrm{H}, \mathrm{dd}, J=0.9,1.2 \mathrm{~Hz}, \mathrm{H} 4), 7.93$ $(1 \mathrm{H}, \mathrm{s}, \mathrm{H} 2), 7.49(1 \mathrm{H}, \mathrm{dd} J=0.9,1.2 \mathrm{~Hz}, \mathrm{H} 7), 7.27-7.17(2 \mathrm{H}, \mathrm{m}, \mathrm{H} 5$ and $\mathrm{H} 6) 6.62\left(2 \mathrm{H}, \mathrm{bs}, \mathrm{NH}_{2}\right)$. 
(E)-Benzylidenehydrazine (25) [80]. Yellow crystal, yield: 88\%; m.p. $92-94{ }^{\circ} \mathrm{C}$ (lit. [80] m.p. 89-90 ${ }^{\circ} \mathrm{C}$ ); ${ }^{1} \mathrm{H}-\mathrm{NMR}\left(\mathrm{CDCl}_{3}\right): \delta 8.72(1 \mathrm{H}, \mathrm{s}, \mathrm{CH}), 7.91-7.88(2 \mathrm{H}, \mathrm{m} \mathrm{ArH}), 7.51-7.49(3 \mathrm{H}, \mathrm{m}, \mathrm{ArH}), 5.63\left(2 \mathrm{H}, \mathrm{bs}, \mathrm{NH}_{2}\right)$.

\subsubsection{General Procedure for EDC Coupling (compounds 14-19, 26-28)}

The appropriate hydrazone 11-13, 23-25 (4 mmol) and substituted carboxylic acid 1-4 (4 mmol) and EDC ( $4.4 \mathrm{mmol})$ were dissolved in dry $\mathrm{N}$ - $\mathrm{N}$-dimethylformamide. Triethylamine $(4.4 \mathrm{mmol})$ was added and the solution was stirred overnight at room temperature. The reaction mixture was diluted with ethyl acetate $(300 \mathrm{~mL})$ and washed with $0.5 \mathrm{M}$ hydrochloric acid solution $(100 \mathrm{~mL})$ and saturated $\mathrm{NaHCO}_{3}$ solution $\left(100 \mathrm{~mL}\right.$ ). The organic phase was dried over $\mathrm{MgSO}_{4}$, filtered and concentrated under reduced pressure to give the title compound.

(E)-N'-((2-Chloroquinolin-3-yl)methylene)-3-(phenylthio)propanehydrazide (14). Yellow solid, yield: 65\%; $\log$ P: 4.79; m.p. $172-174{ }^{\circ} \mathrm{C}$; IR (KBr): $v_{\max } 3181,3070,2960,1668,1616,1598,1571,1486,1436,1409$, 1397, 1328, 1275, $1212 \mathrm{~cm}^{-1}$; UV-vis (MeOH): $\lambda_{\max } 323 \mathrm{~nm}\left(\varepsilon 17,300 \mathrm{~cm}^{-1} \mathrm{M}^{-1}\right), 352$ (7,900); ${ }^{1} \mathrm{H}-\mathrm{NMR}$ $\left(\mathrm{CDCl}_{3}\right): \delta 9.28(1 \mathrm{H}, \mathrm{bs}, \mathrm{NH}), 8.61(1 \mathrm{H}, \mathrm{s}, \mathrm{H} 4), 8.27(1 \mathrm{H}, \mathrm{s}, \mathrm{CH}), 8.06(1 \mathrm{H}, \mathrm{d}, J=8.4 \mathrm{~Hz}, \mathrm{H} 5), 7.92(1 \mathrm{H}$, $\mathrm{d}, J=8.4 \mathrm{~Hz} \mathrm{H8}), 7.84-7.79(1 \mathrm{H}, \mathrm{m}, \mathrm{H} 6)$ 7.68-7.62 $(1 \mathrm{H}, \mathrm{m}, \mathrm{H} 7), 7.46-7.31(5 \mathrm{H}, \mathrm{m}, \mathrm{ArH}) 3.38(2 \mathrm{H}, \mathrm{t}$, $\left.J=7.3 \mathrm{~Hz}, \mathrm{CH}_{2}\right), 3.20\left(2 \mathrm{H}, \mathrm{t}, J=7.3 \mathrm{~Hz}_{\prime \prime} \mathrm{CH}_{2}\right) ;{ }^{13} \mathrm{C}-\mathrm{NMR}\left(\mathrm{CDCl}_{3}\right): \delta 173.43(\mathrm{C}=\mathrm{O}), 148.94(\mathrm{C} 2), 148.54$ (aryl C), $138.96(\mathrm{CH}), 135.67(\mathrm{C} 4), 131.64(\operatorname{aryl} \mathrm{C}), 129.60$ and $129.04(\operatorname{aryl} \mathrm{CH}), 128.50(\mathrm{C7}), 128.37$ (aryl C), 127.77 (C5 and C8), $127.00(\mathrm{C} 6), 126.33(\mathrm{C} 3), 125.72(2 \times$ aryl $\mathrm{CH}), 32.70\left(\mathrm{CH}_{2}\right)$ and $28.61\left(\mathrm{CH}_{2}\right)$ HRMS (ESI): $\mathrm{C}_{16} \mathrm{H}_{17} \mathrm{~N}_{2} \mathrm{O}_{3} \mathrm{~S}[\mathrm{M}]^{+}$requires 285.1062, found 285.1053 .

(E)-N'-((2-Chloro-7-methoxyquinolin-3-yl)methylene)-3-(phenylthio)propanehydrazide (15). Yellow solid, yield: 65\%; $\log$ P: 4.66; m.p. $180-182{ }^{\circ} \mathrm{C}$; IR (KBr): $v_{\max } 3171,3071,2961,1675,1616,1599,1488,1446$, 1407, 1365, 1331, 1274, 1232, 1163, $1126 \mathrm{~cm}^{-1}$; UV-vis (MeOH): $\lambda_{\max } 324 \mathrm{~nm}\left(\varepsilon 15,800 \mathrm{~cm}^{-1} \mathrm{M}^{-1}\right)$, $352(14,600) ;{ }^{1} \mathrm{H}-\mathrm{NMR}\left(\mathrm{CDCl}_{3}\right): \delta 9.37(1 \mathrm{H}, \mathrm{bs}, \mathrm{NH}), 8.51(1 \mathrm{H}, \mathrm{s}, \mathrm{H} 4), 8.24(1 \mathrm{H}, \mathrm{s}, \mathrm{CH}), 7.79(1 \mathrm{H}, \mathrm{d}$, $J=9.0 \mathrm{~Hz}, \mathrm{H} 5), 7.44(1 \mathrm{H}, \mathrm{d}, J=2.4 \mathrm{~Hz}, \mathrm{H} 8), 7.32-7.26(5 \mathrm{H}, \mathrm{m}, \mathrm{ArH}), 7.23(1 \mathrm{H}, \mathrm{dd}, J=2.4,9.0 \mathrm{~Hz}, \mathrm{H} 6)$, $3.99(3 \mathrm{H}, \mathrm{s}, \mathrm{OMe}), 3.37\left(1 \mathrm{H}, \mathrm{t}, J=7.2 \mathrm{~Hz}, \mathrm{CH}_{2}\right), 3.19\left(1 \mathrm{H}, \mathrm{t}, J=7.2 \mathrm{~Hz}, \mathrm{CH}_{2}\right) ;{ }^{13} \mathrm{C}-\mathrm{NMR}\left(\mathrm{CDCl}_{3}\right): \delta$ $171.21(\mathrm{C}=\mathrm{O}), 162.57(\mathrm{C} 2), 150.02(\operatorname{aryl} \mathrm{C}), 149.46(\mathrm{C} 7), 139.45(\mathrm{CH}), 135.78(\mathrm{C} 4), 135.22(\operatorname{aryl} \mathrm{C}), 129.54$ (C5), 129.47, 129.41, 129.20, 129.02, and 126.28 ( $\operatorname{aryl} \mathrm{CH}), 123.02(\operatorname{aryl} \mathrm{C}), 122.26(\mathrm{C} 3), 121.14(\mathrm{C} 6), 106.61$ (C8), $55.76(\mathrm{OMe}), 32.69\left(\mathrm{CH}_{2}\right)$ and $28.62\left(\mathrm{CH}_{2}\right) \mathrm{HRMS}(\mathrm{ESI}): \mathrm{C}_{21} \mathrm{H}_{20} \mathrm{ClN}_{2} \mathrm{O}_{2} \mathrm{SNa}[\mathrm{M}+\mathrm{Na}]^{+}$requires 422.0706, found 422.0697 .

(E)-N'-((2-Chloro-7-methoxyquinolin-3-yl)methylene)-3-phenoxypropanehydrazide (16). Yellow solid, yield: 67\%; $\log$ P: 4.1; m.p. 206-208 ${ }^{\circ} \mathrm{C}$; IR (KBr): $v_{\max } 3186,3065,2932,1674,1619,1600,1489,1458,1400,1365$, 1334, 1292, 1237, 1163, $1127 \mathrm{~cm}^{-1}$; UV-vis $(\mathrm{MeOH}): \lambda_{\max } 322 \mathrm{~nm}\left(\varepsilon 17,500 \mathrm{~cm}^{-1} \mathrm{M}^{-1}\right), 350(16,800)$; ${ }^{1} \mathrm{H}-\mathrm{NMR}\left(\mathrm{CDCl}_{3}\right): \delta 9.30(1 \mathrm{H}, \mathrm{bs}, \mathrm{NH}), 8.63(1 \mathrm{H}, \mathrm{s}, \mathrm{H} 4), 8.26(1 \mathrm{H}, \mathrm{s}, \mathrm{CH}), 7.81(1 \mathrm{H}, \mathrm{d}, J=9.0 \mathrm{~Hz}, \mathrm{H} 5)$, 7.40-7.20 (5H, m, ArH), $7.00(1 \mathrm{H}, \mathrm{d}, J=2.4 \mathrm{~Hz}, \mathrm{H} 8), 6.98(1 \mathrm{H}, \mathrm{dd}, J=2.4,9.0 \mathrm{~Hz}, \mathrm{H6}), 4.47(1 \mathrm{H}, \mathrm{t}$, $\left.J=7.2 \mathrm{~Hz}, \mathrm{CH}_{2}\right), 3,99(3 \mathrm{H}, \mathrm{s}, \mathrm{OMe}), 3.37\left(1 \mathrm{H}, \mathrm{t}, J=7.2 \mathrm{~Hz}, \mathrm{CH}_{2}\right) ;{ }^{13} \mathrm{C}-\mathrm{NMR}\left(\mathrm{CDCl}_{3}\right): \delta 172.65(\mathrm{C}=\mathrm{O})$, $162.59(\mathrm{C} 2), 158.59(\operatorname{aryl} \mathrm{C}), 150.04(\operatorname{aryl} \mathrm{C}), 149.47(\mathrm{C} 7), 139.40(\mathrm{CH}), 135.26(\mathrm{C} 4), 129.75(\mathrm{C}), 129.52$, $129.44(\operatorname{aryl} \mathrm{CH})$ and $123.02(\operatorname{aryl} \mathrm{C}), 122.31(\mathrm{C} 3), 121.15(\operatorname{aryl} \mathrm{CH}), 121.00(\mathrm{C} 6), 114.64(\operatorname{aryl} \mathrm{CH}), 106.61$ (C8), $63.22(\mathrm{CH} 2), 55.76(\mathrm{OMe}), 32.87\left(\mathrm{CH}_{2}\right) \mathrm{HRMS}(\mathrm{ESI}): \mathrm{C}_{21} \mathrm{H}_{21} \mathrm{ClN}_{2} \mathrm{O}_{3}[\mathrm{M}+\mathrm{H}]^{+}$requires 384.1115, found 384.1105 .

(E)-N'-((2-chloro-5,7-dimethoxyquinolin-3-yl)methylene)-3-(phenylthio)propanehydrazide (17). Yellow solid, yield: 63\%; $\log$ P: 4.54; m.p. $168-170{ }^{\circ} \mathrm{C}$; IR (KBr): $v_{\max } 3174,3074,2940,1666,1612,1585,1566,1497$, $1479,1448,1398,1367,1346,1275,1239 \mathrm{~cm}^{-1}$; UV-vis (MeOH): $\lambda_{\max } 313 \mathrm{~nm}\left(\varepsilon 8,700 \mathrm{~cm}^{-1} \mathrm{M}^{-1}\right), 356$ $(8,000) ;{ }^{1} \mathrm{H}-\mathrm{NMR}\left(\mathrm{CDCl}_{3}\right): \delta 8.80(1 \mathrm{H}, \mathrm{s}, \mathrm{CH}), 8.58(1 \mathrm{H}, \mathrm{bs}, \mathrm{NH}) 8.44(1 \mathrm{H}, \mathrm{d}, J=8.1 \mathrm{~Hz}, \mathrm{H6}), 8.41(1 \mathrm{H}, \mathrm{d}$, $J=8.1 \mathrm{~Hz}, \mathrm{H} 8), 7.45-7.42(2 \mathrm{H}, \mathrm{m}, \mathrm{ArH}), 7.32-7.26(3 \mathrm{H}, \mathrm{m}, \mathrm{ArH}), 6.70(1 \mathrm{H}, \mathrm{s}, \mathrm{H} 4), 4.09$ and 4.00 (each $3 \mathrm{H}$, $\mathrm{s}, \mathrm{OMe}), 3.41\left(2 \mathrm{H}, \mathrm{t}, J=7.2 \mathrm{~Hz}, \mathrm{CH}_{2}\right), 3.17\left(2 \mathrm{H}, \mathrm{t}, J=7.2 \mathrm{~Hz}_{\prime \prime} \mathrm{CH}_{2}\right) ;{ }^{13} \mathrm{C}-\mathrm{NMR}\left(\mathrm{CDCl}_{3}\right): \delta 172.89(\mathrm{C}=\mathrm{O})$, 160.85 (C7), 157.56 (C5), 152.15 (C2), 148.65 (aryl C), $139.93(\mathrm{CH}), 135.92$ (aryl C) 134.01 (C4), 129.47, 129.21, $128.28(\operatorname{aryl} \mathrm{CH}), 125.59(\operatorname{aryl} \mathrm{CH}), 119.56(\mathrm{C} 3), 114.36(\operatorname{aryl} \mathrm{C}), 108.54(\mathrm{C} 6), 93.74(\mathrm{C} 8), 56.65$ 
(OMe), $56.01(\mathrm{OMe}), 33.65\left(\mathrm{CH}_{2}\right)$ and 28.44 $\left(\mathrm{CH}_{2}\right) \mathrm{HRMS}$ (ESI): $\mathrm{C}_{21} \mathrm{H}_{20} \mathrm{ClN}_{3} \mathrm{O}_{3} \mathrm{SNa}[\mathrm{M}+\mathrm{Na}]^{+}$requires 452.0812 , found 452.0806 .

(E)-N'-((2-Chloro-7-methoxyquinolin-3-yl)methylene)-6-(phenylthio)hexanehydrazide (18). Yellow solid, yield: $68 \%$; $\log$ P: 5.78; m.p. $138-140{ }^{\circ} \mathrm{C}$; IR (KBr): $v_{\max } 3202,3052,2928,1669,1622,1597,1566$, 1550, 1491, 1479, 1465, 1436, 1363, 1334, $1260 \mathrm{~cm}^{-1}$; UV-vis (MeOH): $\lambda_{\max } 322 \mathrm{~nm}\left(\varepsilon 18,100 \mathrm{~cm}^{-1} \mathrm{M}^{-1}\right)$, $352(16,900) ;{ }^{1} \mathrm{H}-\mathrm{NMR}\left(\mathrm{CDCl}_{3}\right): \delta 9.18(1 \mathrm{H}, \mathrm{bs}, \mathrm{NH}), 8.63(1 \mathrm{H}, \mathrm{s}, \mathrm{H} 4), 8.22(1 \mathrm{H}, \mathrm{s}, \mathrm{CH}), 7.81(1 \mathrm{H}, \mathrm{d}$, $J=9.0 \mathrm{~Hz}, \mathrm{H} 5), 7.40-7.20(5 \mathrm{H}, \mathrm{m}, \mathrm{ArH}), 7.19(1 \mathrm{H}, \mathrm{d}, J=2.4 \mathrm{~Hz}, \mathrm{H} 8), 7.18(1 \mathrm{H}, \mathrm{dd}, J=2.4,9.0 \mathrm{~Hz}, \mathrm{H} 6)$, $3,99(3 \mathrm{H}, \mathrm{s}, \mathrm{OMe}), 2.99\left(2 \mathrm{H}, \mathrm{t}, J=7.6 \mathrm{~Hz}, \mathrm{CH}_{2}\right), 2.84\left(2 \mathrm{H}, \mathrm{t}, J=7.6 \mathrm{~Hz}, \mathrm{CH}_{2}\right), 1.85-1.73\left(4 \mathrm{H}, \mathrm{m}, \mathrm{CH}_{2}-\mathrm{CH}_{2}\right)$, 1.67-1.60 (4H, m, $\left.\mathrm{CH}_{2}\right) ;{ }^{13} \mathrm{C}-\mathrm{NMR}\left(\mathrm{CDCl}_{3}\right): \delta 175.42(\mathrm{C}=\mathrm{O}), 162.52(\mathrm{C} 2), 149.96(\operatorname{aryl~C}), 149.46(\mathrm{C} 7)$, $138.79(\mathrm{CH}), 136.76(\mathrm{C} 4), 135.10$ (aryl C), $129.42(\mathrm{C} 5), 129.06,128.94,128.86,125.77(\operatorname{aryl~CH}), 123.23$ (aryl C), $122.33(\mathrm{C} 3), 121.10(\mathrm{C} 6), 106.60(\mathrm{C} 8), 55.76(\mathrm{OMe}), 33.46(\mathrm{CH} 2), 32.50\left(\mathrm{CH}_{2}\right), 28.90\left(\mathrm{CH}_{2}\right)$ 28.48, 28.28 and 24.08( $\left(\mathrm{CH}_{2}\right)$ HRMS (ESI): $\mathrm{C}_{23} \mathrm{H}_{24} \mathrm{ClN}_{3} \mathrm{O}_{2} \mathrm{SNa}[\mathrm{M}+\mathrm{Na}]^{+}$requires 464.1163, found 464.1170.

(E)-N'-((2-Chloro-7-methoxyquinolin-3-yl)methylene)-6-phenoxyhexanehydrazide (19). Yellow solid, yield: 62\%; $\log$ P: 5.21; m.p. $134-136{ }^{\circ} \mathrm{C}$; IR (KBr): $v_{\max } 3191,3082,2932,1667,1618,1490,1467,1399$, 1337, 1286, 1232, 1164, 1127, 1105, $1081 \mathrm{~cm}^{-1}$; UV-vis (MeOH): $\lambda_{\max } 323 \mathrm{~nm}\left(\varepsilon 18,200 \mathrm{~cm}^{-1} \mathrm{M}^{-1}\right)$, $350(17,200) ;{ }^{1} \mathrm{H}-\mathrm{NMR}\left(\mathrm{CDCl}_{3}\right): \delta 9.32(1 \mathrm{H}, \mathrm{bs}, \mathrm{NH}), 8.63(1 \mathrm{H}, \mathrm{s}, \mathrm{H} 4), 8.24(1 \mathrm{H}, \mathrm{s}, \mathrm{CH}), 7.79(1 \mathrm{H}, \mathrm{d}$, $J=9.0 \mathrm{~Hz}, \mathrm{H} 5), 7.35(1 \mathrm{H}, \mathrm{d}, J=2.4 \mathrm{~Hz}, \mathrm{H} 8), 7.31-7.23(5 \mathrm{H}, \mathrm{m}, \mathrm{ArH}), 6.92(1 \mathrm{H}, \mathrm{dd}, J=2.4,9.0 \mathrm{~Hz}$, H6), $4.02\left(2 \mathrm{H}, \mathrm{t}, J=7.6 \mathrm{~Hz}, \mathrm{CH}_{2}\right), 3,99(3 \mathrm{H}, \mathrm{s}, \mathrm{OMe}), 2.88\left(2 \mathrm{H}, \mathrm{t}, J=7.6 \mathrm{~Hz}, \mathrm{CH}_{2}\right), 1.94-1.87(4 \mathrm{H}, \mathrm{m}$, $\left.\mathrm{CH}_{2}-\mathrm{CH}_{2}\right), 1.67-1.65\left(4 \mathrm{H}, \mathrm{m}, \mathrm{CH}_{2}\right) ;{ }^{13} \mathrm{C}-\mathrm{NMR}\left(\mathrm{CDCl}_{3}\right): \delta 175.54(\mathrm{C}=\mathrm{O}), 162.50(\mathrm{C} 2), 159.03(\operatorname{aryl} \mathrm{C})$, 149.95 (aryl C), $149.46(\mathrm{C} 7), 138.79(\mathrm{CH}), 135.09$ (C4), 129.43 ( C5) and $123.26(\operatorname{aryl} \mathrm{C}), 122.33$ (C3), 121.09 $(2 \times$ aryl $\mathrm{CH}), 120.56(\mathrm{C} 6), 114.47(2 \times$ aryl $\mathrm{CH}), 106.59(\mathrm{C} 8), 67.61(\mathrm{CH} 2), 55.75(\mathrm{OMe}), 32.87\left(\mathrm{CH}_{2}\right)$, 29.15, 25.91 and $24.33\left(\mathrm{CH}_{2}\right)$ HRMS (ESI): $\mathrm{C}_{23} \mathrm{H}_{25} \mathrm{ClN}_{3} \mathrm{O}_{3}[\mathrm{M}+\mathrm{H}]^{+}$requires 426.1575, found 426.1579 .

(E)-N'-(Naphthalen-2-ylmethylene)-3-(phenylthio)propanehydrazide (26). Yellow solid, yield: 72\%; log P: 4.8; m.p. 166-168 ${ }^{\circ} \mathrm{C}$; IR (KBr): $v_{\max } 3325,3276,1686,1550,1501,1441,1284,1220,1237,1002,832,719$, $760 \mathrm{~cm}^{-1}$; UV-vis (MeOH): $\lambda_{\max } 300 \mathrm{~nm}\left(\varepsilon 30,300 \mathrm{~cm}^{-1} \mathrm{M}^{-1}\right), 309(36,100) ;{ }^{1} \mathrm{H}-\mathrm{NMR}\left(\mathrm{CDCl}_{3}\right): \delta 9.40$ $(1 \mathrm{H}, \mathrm{s}, \mathrm{CH}), 7.94-7.87$ (5H, m, ArH,), 7.58-7.55 (2H, m, H6 and H7 npthl.), 7.49-7.46 (2H, m, ArH), 7.37-7.32 (2H, m, ArH). 7.28-7.25 (1H, m, ArH), $3.38\left(2 \mathrm{H}, \mathrm{t}, J=7.2 \mathrm{~Hz}, \mathrm{CH}_{2}\right), 3.21(2 \mathrm{H}, \mathrm{t}, J=7.2 \mathrm{~Hz}$, $\left.\mathrm{CH}_{2}\right) ;{ }^{13} \mathrm{C}-\mathrm{NMR}\left(\mathrm{CDCl}_{3}\right): \delta 173.73(\mathrm{C}=\mathrm{O}), 143.98(\mathrm{CH}), 135.84(\operatorname{aryl} \mathrm{C}), 134.32(\operatorname{aryl} \mathrm{C}), 133.12(\operatorname{aryl} \mathrm{C})$, 129.79 and $129.04(2 \times \operatorname{aryl} \mathrm{CH}), 128.70(\mathrm{C} 2), 128.37$ (C5), $127.93(\mathrm{C} 8), 127.21(\mathrm{C} 4), 126.75$ (C1 and C3), $126.33(\mathrm{C} 6$ and $\mathrm{C} 7), 122.71(\operatorname{aryl~CH}), 32.97\left(\mathrm{CH}_{2}\right)$ and $28.90\left(\mathrm{CH}_{2}\right)$ HRMS (ESI): $\mathrm{C}_{20} \mathrm{H}_{19} \mathrm{~N}_{2} \mathrm{OS}[\mathrm{M}+\mathrm{H}]^{+}$ requires 335.1218 , found 335.1213 .

(E)-N'-((1H-Indol-3-yl)methylene)-3-(phenylthio)propanehydrazide (27). Yellow solid, yield: 58\%; log P: 3.35; m.p. 226-228 ${ }^{\circ} \mathrm{C}$; IR (KBr): $v_{\max } 3385,3134,3060,2917,1721,1624,1521,1490,1448,1438,1390$, 1364, 1330, 1299, $1231 \mathrm{~cm}^{-1}$; UV-vis $(\mathrm{MeOH}): \lambda_{\max } 344 \mathrm{~nm}\left(\varepsilon 38,600 \mathrm{~cm}^{-1} \mathrm{M}^{-1}\right),{ }^{1} \mathrm{H}-\mathrm{NMR}\left(\mathrm{CDCl}_{3}\right): \delta$ $9.04(1 \mathrm{H}, \mathrm{bs}, \mathrm{NH}), 8.91(1 \mathrm{H}, \mathrm{bs}, \mathrm{NH}), 8.88(1 \mathrm{H}, \mathrm{s}, \mathrm{CH}), 8.48(1 \mathrm{H}, \mathrm{s}, \mathrm{H} 2), 8.45(1 \mathrm{H}, \mathrm{dd}, J=0.9,1.2 \mathrm{~Hz}$, $\mathrm{H} 4), 8.29(1 \mathrm{H}, \mathrm{dd} J=0.9,1.2 \mathrm{~Hz}, \mathrm{H} 7), 7.51-7.41(5 \mathrm{H}, \mathrm{m}, \mathrm{ArH}) 7.36-7.23(2 \mathrm{H}, \mathrm{m}, \mathrm{H} 5 \mathrm{and} \mathrm{H} 6), 3.48(2 \mathrm{H}, \mathrm{t}$, $\left.J=7.2 \mathrm{~Hz}, \mathrm{CH}_{2}\right), 3.32\left(2 \mathrm{H}, \mathrm{t}, J=7.2 \mathrm{~Hz}, \mathrm{CH}_{2}\right) ;{ }^{13} \mathrm{C}-\mathrm{NMR}\left(\mathrm{CDCl}_{3}\right): \delta 170.93(\mathrm{C}=\mathrm{O}), 153.95(\mathrm{CH}), 137.74$ (aryl C), $136.52(\operatorname{aryl} \mathrm{C}), 131.06(\mathrm{C} 2), 129.67(2 \times \operatorname{aryl} \mathrm{CH}), 128.59(2 \times \operatorname{aryl} \mathrm{CH}), 125.45(\operatorname{aryl} \mathrm{C}), 126.34$ (CH), 121.78 (C4 and $\mathrm{C} 6), 117.98$ (C5), $112.57(\mathrm{C} 7), 112.20(\mathrm{C} 3) 36.80\left(\mathrm{CH}_{2}\right)$ and $27.51\left(\mathrm{CH}_{2}\right)$ HRMS (ESI): $\mathrm{C}_{18} \mathrm{H}_{19} \mathrm{~N}_{3} \mathrm{OS}[\mathrm{M}+\mathrm{H}]^{+}$requires 324.1171 , found 324.1163 .

(E)-N'-Benzylidene-3-(phenylthio)propanehydrazide (28). Yellow solid, yield: 68\%; log P: 3.81; m.p. 104-106 ${ }^{\circ} \mathrm{C}$; IR (KBr): $v_{\max } 3176,3089,2965,1667,1607,1583,1571,1481,1438,1423,1356,1315$, 1298, $1263 \mathrm{~cm}^{-1}$; UV-vis $(\mathrm{MeOH}): \lambda_{\max } 301 \mathrm{~nm}\left(\varepsilon 11,000 \mathrm{~cm}^{-1} \mathrm{M}^{-1}\right) ;{ }^{1} \mathrm{H}-\mathrm{NMR}\left(\mathrm{CDCl}_{3}\right): \delta 10.21$ $(1 \mathrm{H}, \mathrm{bs}, \mathrm{NH}), 7.87(1 \mathrm{H}, \mathrm{s}, \mathrm{CH}), 7.65-7.62(2 \mathrm{H}, \mathrm{m} \mathrm{ArH}), 7.47(1 \mathrm{H}, \mathrm{m}, \mathrm{ArH}), 7.45-7.42(4 \mathrm{H}, \mathrm{m}, \mathrm{ArH})$, 7.36-7.24 (3H, m, ArH), $3.35\left(2 \mathrm{H}, \mathrm{t}, J=7.2 \mathrm{~Hz}, \mathrm{CH}_{2}\right), 3.16\left(2 \mathrm{H}, \mathrm{t}, J=7.2 \mathrm{~Hz}, \mathrm{CH}_{2}\right) ;{ }^{13} \mathrm{C}-\mathrm{NMR}\left(\mathrm{CDCl}_{3}\right)$ : $\delta 174.37(\mathrm{C}=\mathrm{O}), 144.40(\mathrm{CH}), 135.85(\operatorname{aryl} \mathrm{C}), 133.70(\mathrm{C} 1), 130.23(\mathrm{C} 5), 129.78$ (C2 and $\mathrm{C} 3), 129.02$ (aryl C), $128.75(\mathrm{C} 4$ and $\mathrm{C} 6), 127.26(2 \times$ aryl $\mathrm{CH}), 126.31(2 \times$ aryl $\mathrm{CH}), 32.97$ and $28.97\left(\mathrm{CH}_{2}\right)$ HRMS (ESI): $\mathrm{C}_{16} \mathrm{H}_{16} \mathrm{~N}_{2} \mathrm{OSNa}[\mathrm{M}+\mathrm{Na}]^{+}$requires 307.0881, found 307.0872 . 


\subsection{Cell Biology Techniques}

The SH-SY5Y and Kelly human neuroblastoma cell lines were generously donated by Dr. J. Biedler (Memorial Sloan-Kettering Cancer Center, New York, NY, USA). The MDA-MB-231 and MCF-7 breast cancer cell lines were purchased from the American Type Culture Collection. All cell lines were cultured under standard conditions at $37{ }^{\circ} \mathrm{C}$ in $5 \% \mathrm{CO}_{2}$ as an adherent monolayer in Dulbecco's modified Eagle's medium supplemented with L-glutamine (DMEM) (Invitrogen, Waltham, MA, USA) and 10\% fetal calf serum (FCS) (Thermo Fisher Scientific, Waltham, MA, USA).

\subsubsection{Method for Cell Viability Assays}

Cell viability was measured by the standard Alamar blue assay, as previously described [34]. Briefly, cells were allowed to attach for $24 \mathrm{~h}$ in 96-well culture plates. The cells were then continuously exposed to serial dilutions of the hydrazide-hydrazone derivatives for $72 \mathrm{~h}$, either in the presence or absence of SAHA $(0.5$ or $1 \mu \mathrm{M})$, with five replicate wells for each determination. Cell viability was determined by the addition of $22 \mu \mathrm{L}$ of Alamar blue reagent, recorded at comparative $0 \mathrm{~h}$ and $5 \mathrm{~h}$ values, using a Wallac 1420 Victor III spectrophotometer (GMI, Ramsey, MN, USA), which measured light absorbance in each well at $570 \mathrm{~nm}$. The cell viability of each plate was calculated as a percentage compared to matched DMSO controls $(0.5 \%)$. The mean $(+/-\mathrm{SEM})$ is shown for three independent experiments.

\subsubsection{Cell Cycle Study by Propidium Iodide Staining}

The cell cycle phase distribution of a cell population was determined by measuring cell DNA content using flow cytometry with propidium iodide (PI) (Sigma Aldrich) staining. The cells were trypsinized and resuspended at a concentration of $1 \times 10^{6}$ in a complete medium, then pelleted by cold centrifugation at 1200 r.p.m., rinsed with PBS and recollected as a cell pellet. The cells were then resuspended in $0.1 \mathrm{~mL}$ cold PBS and were fixed in $80 \%$ cold ethanol by adding $1 \mathrm{~mL}$ on top of the cell suspension and incubated at $4{ }^{\circ} \mathrm{C}$ for $30 \mathrm{~min}$. Prior to flow cytometric analysis, the cells were pelleted and the entire supernatant carefully discarded. The samples were treated with RNase A (Sigma, Sydney, NSW, Australia) for $30 \mathrm{~min}$ at room temperature and then stained with propidium iodide ( $50 \mu \mathrm{g} / \mathrm{mL}$, final concentration) for $45 \mathrm{~min}$ at room temperature. The samples were analysed using a BD Caliber Flow cytometer (BD, San Jose, CA, USA). The cell cycle analysis was performed in FlowJo. Cell populations were divided into three subsets of cells that represented the sub $G_{0} / G_{1}$, $\mathrm{G}_{0} / \mathrm{G}_{1}$ phase, $S$ phase and $\mathrm{G}_{2} / \mathrm{M}$ (as determined from comparison with untreated cell control gating).

\subsubsection{Immunoblotting of Cell Cycle Regulatory Protein Expression}

Whole-cell lysates were prepared in RIPA buffer as described [81]. $20 \mu \mathrm{g}$ of lysates were loaded onto Criterion Gels TRIS-HCl 10\%-14\% Polyacrylamide gels (Bio-Rad, NSW, Australia). Antibodies used were p27kip1 (1/500, BD), pRb (1/500, Cell Signaling, San Jose, CA, USA), E2F1 (1/500, Zymed, Waltham, MA, USA), and $\alpha$-tubulin (1/2000, Sigma-Aldrich, Sydney, NSW, Australia) as loading control.

\subsection{Statistical Analysis}

Results of the cell viability studies were statistically analyzed using the two-tailed, unpaired Student's t-test. Results are expressed as mean values with 95\% confidence intervals.

\section{Conclusions}

The quinoline-hydrazide-hydrazone motif was identified in a library screen as a promising lead scaffold for anti-cancer activity against neuroblastoma cells. This work describes the synthesis of a series of related quinoline hydrazide-hydrazones as well as three derivatives containing different aromatic systems, via an EDC-mediated coupling. The methodology involved the simple reaction 
of hydrazones with substituted carboxylic acids under EDC-mediated conditions. Preliminary SAR investigations revealed that the presence of a bicyclic system comprised of 6-membered rings is favoured for activity. Furthermore, the presence of methoxy groups was found to increase activity, as was exchange of the use of an ether linkage, rather than a sulfane. The two most potent analogues 16 and 17 showed low micromolar potency against neuroblastoma cells. Furthermore, these two compounds displayed significant selectivity for neuroblastoma cancer cells over normal human lung fibroblast cells. It was also found that compound $\mathbf{1 7}$ induced upregulation of the cell cycle mediator p27 ${ }^{\text {kip1 }}$, with a corresponding cell cycle arrest at $G_{1}$ in SH-SY5Y neuroblastoma cells.

Acknowledgments: We thank the University of New South Wales, and the Australian Research Council (ARC) for funding to N.K and D.StC.B. Mass spectrometric analysis for this work was carried out at the Bioanalytical Mass Spectrometry Facility, UNSW and was supported in part by infrastructure funding from the New South Wales Government as part of its co-investment in the National Collaborative Research Infrastructure Strategy. This research was supported by Australian Postgraduate Research Scholarships, University of NSW, Program Grants from the NHMRC Australia, Cancer Institute NSW Australia and Cancer Council NSW Australia. The Children's Cancer Institute Australia for Medical Research is affiliated with the University of NSW and Sydney Children's Hospital.

Author Contributions: N.K., D.StC.B. and B.C. conceived and designed the experiments, G.M.A. provided the data from library screening, M.B., S.S., O.T. and C.R.G. performed the experiments, analyzed and interpreted the data, M.B. and C.R.G. wrote the paper, N.K. and G.M. supported financially.

Conflicts of Interest: The authors declare no conflict of interest.

\section{Abbreviations}

The following abbreviations are used in this manuscript:

$\begin{array}{ll}\text { EDC } & \text { 1-ethyl-3-(3-dimethylaminopropyl)carbodiimide hydrochloride } \\ \text { HDACi } & \text { Histone deacetylase inhibitors } \\ \text { SAHA } & \text { Suberoylanilide hydroxamic acid } \\ \text { WEHI } & \text { Walter \& Eliza Hall Institute } \\ \text { DMF } & \text { Dimethylformamide } \\ \text { SD } & \text { Standart Deviation } \\ \text { DMSO } & \text { Dimethylsulfoxide } \\ \text { DMAP } & \text { Dimethoxyaminopyridine } \\ \text { KBr } & \text { Potassium Bromide } \\ \text { Et }_{3} N & \text { Triethylamine } \\ \text { PI } & \text { Propidium iodide } \\ \text { SEM } & \text { Standart Error of Mean } \\ \text { ORTEP } & \text { Oak Ridge thermal ellipsoid }\end{array}$

\section{References and Notes}

1. Hanahan, D.; Weinberg, R.A. The hallmarks of cancer. Cell 2000, 100, 57-70. [CrossRef]

2. Lautz, T.B.; Jie, C.; Clark, S.; Naiditch, J.A.; Jafari, N.; Qiu, Y.Y.; Zheng, X.; Chu, F.; Madonna, M.B. The effect of vorinostat on the development of resistance to doxorubicin in neuroblastoma. PLOS ONE 2012, 7, e40816. [CrossRef] [PubMed]

3. Lee, J.H.; Choy, M.L.; Marks, P.A. Mechanisms of Resistance to Histone Deacetylase Inhibitors. In Advances in Cancer Research; Steven, G., Ed.; Academic Press: San Diego, CA, USA, 2012; Volume 116, pp. $39-86$.

4. Richon, V.M. Cancer biology: Mechanism of antitumour action of vorinostat (suberoylanilide hydroxamic acid), a novel histone deacetylase inhibitor. Br. J. Cancer 2006, 95, 2-6. [CrossRef]

5. Basu, H.S.; Mahlum, A.; Mehraein-Ghomi, F.; Kegel, S.J.; Guo, S.; Peters, N.R.; Wilding, G. Pre-treatment with anti-oxidants sensitizes oxidatively stressed human cancer cells to growth inhibitory effect of suberoylanilide hydroxamic acid (SAHA). Cancer Chemother. Pharmacol. 2011, 67, 705-715. [CrossRef] [PubMed]

6. Mann, B.S.; Johnson, J.R.; He, K.; Sridhara, R.; Abraham, S.; Booth, B.P.; Verbois, L.; Morse, D.E.; Jee, J.M.; Pope, S.; et al. Vorinostat for treatment of cutaneous manifestations of advanced primary cutaneous T-cell lymphoma. Clin. Cancer Res. 2007, 13, 2318-2322. [CrossRef] [PubMed] 
7. Kelly, W.K.; O'Connor, O.A.; Krug, L.M.; Chiao, J.H.; Heaney, M.; Curley, T.; MacGregore-Cortelli, B.; Tong, W.; Secrist, J.P.; Schwartz, L.; et al. Phase I study of an oral histone deacetylase inhibitor, suberoylanilide hydroxamic acid, in patients with advanced cancer. J. Clin. Oncol. 2005, 23, 3923-3931. [CrossRef] [PubMed]

8. Rundall, B.K.; Denlinger, C.E.; Jones, D.R. Combined histone deacetylase and NF- $\kappa$ B inhibition sensitizes non-small cell lung cancer to cell death. Surgery 2005, 138, 360-367. [CrossRef] [PubMed]

9. Sonnemann, J.; Gange, J.; Kumar, K.S.; Muller, C.; Bader, P.; Beck, J.F. Histone deacetylase inhibitors interact synergistically with tumor necrosis factor-related apoptosis-inducing ligand (TRAIL) to induce apoptosis in carcinoma cell lines. Investig. New Drug 2005, 23, 99-109. [CrossRef] [PubMed]

10. Denlinger, C.E.; Rundall, B.K.; Jones, D.R. Proteasome inhibition sensitizes non-small cell lung cancer to histone deacetylase inhibitor-induced apoptosis through the generation of reactive oxygen species. J Thorac. Cardiov. Sur. 2004, 128, 740-748. [CrossRef] [PubMed]

11. Arndt, G.; (Children's Cancer Institute, Sydney, NSW, Australia). Personal Communication, 2009.

12. Eicher, T.; Hauptmann, S. The Chemistry of Heterocycles, 2nd ed.; Wiley-VCH: Weinheim, Germany, 2003; pp. 316-336.

13. Chen, Y.L.; Huang, C.J.; Huang, Z.Y.; Tseng, C.H.; Chang, F.S.; Yang, S.H.; Lin, S.R.; Tzeng, C.C. Synthesis and antiproliferative evaluation of certain 4-anilino-8-methoxy-2-phenylquinoline and 4-anilino-8-hydroxy-2-phenylquinoline derivatives. Bioorg. Med. Chem. 2006, 14, 3098-3105. [CrossRef] [PubMed]

14. Chen, Y.L.; Zhao, Y.L.; Lu, C.M.; Tzeng, C.C.; Wang, J.P. Synthesis, cytotoxicity, and anti-inflammatory evaluation of 2-(furan-2-yl)-4-(phenoxy)quinoline derivatives. Bioorg. Med. Chem. 2006, 14, 4373-4378. [CrossRef] [PubMed]

15. Feng, Y.; Lau, E.; Scortegagna, M.; Ruller, C.; De, S.K.; Barile, E.; Krajewski, S.; Aza-Blanc, P.; Williams, R.; Pinkerton, A.B.; et al. Inhibition of melanoma development in the $\operatorname{Nras}(\mathrm{Q} 61 \mathrm{~K})$ : Ink4a(-/-) mouse model by the small molecule BI-69A11. Pigm. Cell Melanoma Res. 2013, 26, 136-142. [CrossRef] [PubMed]

16. Gholap, A.R.; Toti, K.S.; Shirazi, F.; Kumari, R.; Bhat, M.K.; Deshpande, M.V.; Srinivasan, K.V. Synthesis and evaluation of antifungal properties of a series of the novel 2-amino-5-oxo-4-phenyl5,6,7,8-tetrahydroquinoline-3-carbonitrile and its analogues. Bioorg. Med. Chem. 2007, 15, 6705-6715. [CrossRef] [PubMed]

17. Krafts, K.; Hempelmann, E.; Skorska-Stania, A. From methylene blue to chloroquine: A brief review of the development of an antimalarial therapy. Parasitol. Res. 2012, 111, 1-6. [CrossRef] [PubMed]

18. Sanchez, J.P.; Domagala, J.M.; Hagen, S.E.; Heifetz, C.L.; Hutt, M.P.; Nichols, J.B.; Trehan, A.K. Quinolone antibacterial agents. Synthesis and structure-activity relationships of 8-substituted quinoline-3-carboxylic acids and 1,8-naphthyridine-3-carboxylic acids. J. Med. Chem. 1988, 31, 983-991. [CrossRef] [PubMed]

19. Adsule, S.; Barve, V.; Chen, D.; Ahmed, F.; Dou, Q.P.; Padhye, S.; Sarkar, F.H. Novel Schiff base copper complexes of quinoline-2 carboxaldehyde as proteasome inhibitors in human prostate cancer cells. J. Med. Chem. 2006, 49, 7242-7246. [CrossRef] [PubMed]

20. Nakamura, T.; Oka, M.; Aizawa, K.; Soda, H.; Fukuda, M.; Terashi, K.; Ikeda, K.; Mizuta, Y.; Noguchi, Y.; Kimura, Y.; et al. Direct interaction between a quinoline derivative, MS-209, and multidrug resistance protein (MRP) in human gastric cancer cells. Biochem. Bioph. Res. Co. 1999, 255, 618-624. [CrossRef] [PubMed]

21. Reddy, B.S.; Rivenson, A. Inhibitory effect of Bifidobacterium longum on colon, mammary, and liver carcinogenesis induced by 2-amino-3-methylimidazo[4,5-f]quinoline, a food mutagen. Cancer Res. 1993, 53, 3914-3918. [PubMed]

22. Shi, A.; Nguyen, T.A.; Battina, S.K.; Rana, S.; Takemoto, D.J.; Chiang, P.K.; Hua, D.H. Synthesis and anti-breast cancer activities of substituted quinolones. Bioorg. Med. Chem. Lett. 2008, 18, 3364-3368. [CrossRef] [PubMed]

23. Wall, M.E.; Wani, M.C.; Cook, C.E.; Palmer, K.H.; McPhail, A.T.; Sim, G.A. Plant Antitumor Agents. I. The Isolation and Structure of Camptothecin, a Novel Alkaloidal Leukemia and Tumor Inhibitor from Camptotheca acuminata ${ }^{1,2}$. J. Am. Chem. Soc. 1966, 88, 3888-3890. [CrossRef]

24. Sawada, S.; Okajima, S.; Aiyama, R.; Nokata, K.I.; Furuta, T.; Yokokura, T.; Sugino, E.; Yamaguchi, K.; Miyasaka, T. Synthesis and antitumor activity of 20(S)-camptothecin derivatives: Carbamate-linked, water-soluble derivaties of 7-ethyl-10-hydroxycamptothecin. Chem. Pharm. Bull. 1991, 39, 1446-1454. [CrossRef] [PubMed] 
25. Cortes, J.E.; Kantarjian, H.M.; Brummendorf, T.H.; Kim, D.W.; Turkina, A.G.; Shen, Z.X.; Pasquini, R.; Khoury, H.J.; Arkin, S.; Volkert, A.; et al. Safety and efficacy of bosutinib (SKI-606) in chronic phase Philadelphia chromosome-positive chronic myeloid leukemia patients with resistance or intolerance to imatinib. Blood 2011, 118, 4567-4576. [CrossRef] [PubMed]

26. Cortes, J.E.; Kim, D.-W.; Kantarjian, H.M.; Brümmendorf, T.H.; Dyagil, I.; Griskevicius, L.; Malhotra, H.; Powell, C.; Gogat, K.; Countouriotis, A.M.; et al. Bosutinib Versus Imatinib in Newly Diagnosed Chronic-Phase Chronic Myeloid Leukemia: Results From the BELA Trial. J. Clin. Oncol. 2012, 30, 3486-3492. [CrossRef] [PubMed]

27. Ajani, O.O.; Obafemi, C.A.; Nwinyi, O.C.; Akinpelu, D.A. Microwave-assisted synthesis and antimicrobial activity of 2-quinoxalinone-3-hydrazone derivatives. Bioorg. Med. Chem. 2010, 18, 214-221. [CrossRef] [PubMed]

28. Melnyk, P.; Leroux, V.; Sergheraert, C.; Grellier, P. Design, synthesis and in vitro antimalarial activity of an acylhydrazone library. Bioorg. Med. Chem. Lett. 2006, 16, 31-35. [CrossRef] [PubMed]

29. Zheng, L.W.; Wu, L.L.; Zhao, B.X.; Dong, W.L.; Miao, J.Y. Synthesis of novel substituted pyrazole-5-carbohydrazide hydrazone derivatives and discovery of a potent apoptosis inducer in A549 lung cancer cells. Bioorg. Med. Chem. 2009, 17, 1957-1962. [CrossRef] [PubMed]

30. Metwally, K.A.; Abdel-Aziz, L.M.; Lashine, E.S.M.; Husseiny, M.I.; Badawy, R.H. Hydrazones of 2-aryl-quinoline-4-carboxylic acid hydrazides: Synthesis and preliminary evaluation as antimicrobial agents. Bioorg. Med. Chem. 2006, 14, 8675-8682. [CrossRef] [PubMed]

31. Eswaran, S.; Adhikari, A.V.; Pal, N.K.; Chowdhury, I.H. Design and synthesis of some new quinoline-3-carbohydrazone derivatives as potential antimycobacterial agents. Bioorg. Med. Chem. Lett. 2010, 20, 1040-1044. [CrossRef] [PubMed]

32. Nayyar, A.; Monga, V.; Malde, A.; Coutinho, E.; Jain, R. Synthesis, anti-tuberculosis activity, and 3D-QSAR study of 4-(adamantan-1-yl)-2-substituted quinolines. Bioorg. Med. Chem. 2007, 15, 626-640. [CrossRef] [PubMed]

33. Thomas, K.D.; Adhikari, A.V.; Telkar, S.; Chowdhury, I.H.; Mahmood, R.; Pal, N.K.; Row, G.; Sumesh, E. Design, synthesis and docking studies of new quinoline-3-carbohydrazide derivatives as anti-tubercular agents. Eur. J. Med. Chem. 2011, 46, 5283-5292. [CrossRef] [PubMed]

34. Kumar, S.; Bawa, S.; Drabu, S.; Kumar, R.; Machawal, L. Synthesis and in vivo anti-convulsant evaluation of 2-chloroquinolinyl hydrazone derivatives. Acta. Pol. Pharmaceutica 2010, 67, 567-573.

35. Reddy, L.V.; Nallapati, S.B.; Beevi, S.S.; Mangamoori, L.N.; Mukkanti, K.; Pal, S. A "green" synthesis of $\mathrm{N}$-(quinoline-3-ylmethylene)benzohydrazide derivatives and their cytotoxicity activities. J. Brazil. Chem. Soc. 2011, 22, 1742-1749. [CrossRef]

36. You, Q.D.; Li, Z.Y.; Huang, C.H.; Yang, Q.; Wang, X.J.; Guo, Q.L.; Chen, X.G.; He, X.G.; Li, T.K.; Chern, J.W. Discovery of a novel series of quinolone and naphthyridine derivatives as potential topoisomerase I inhibitors by scaffold modification. J. Med. Chem. 2009, 52, 5649-5661. [CrossRef] [PubMed]

37. Weiss, M.M.; Harmange, J.C.; Polverino, A.J.; Bauer, D.; Berry, L.; Berry, V.; Borg, G.; Bready, J.; Chen, D.; Choquette, D.; et al. Evaluation of a series of naphthamides as potent, orally active vascular endothelial growth factor receptor-2 tyrosine kinase inhibitors. J. Med. Chem. 2008, 51, 1668-1680. [CrossRef] [PubMed]

38. Chen, H.; Yang, Z.; Ding, C.; Chu, L.; Zhang, Y.; Terry, K.; Liu, H.; Shen, Q.; Zhou, J. Fragment-based drug design and identification of HJC0123, a novel orally bioavailable STAT3 inhibitor for cancer therapy. Eur. J. Med. Chem. 2013, 62, 498-507. [CrossRef] [PubMed]

39. Moffat, D.; Patel, S.; Day, F.; Belfield, A.; Donald, A.; Rowlands, M.; Wibawa, J.; Brotherton, D.; Stimson, L.; Clark, V.; et al. Discovery of 2-(6-\{[(6-fluoroquinolin-2-yl)methyl] amino\}bicyclo[3.1.0]hex-3-yl)$\mathrm{N}$-hydroxypyrimidine-5-carboxamide (CHR-3996), a class I selective orally active histone deacetylase inhibitor. J. Med. Chem. 2010, 53, 8663-8678. [CrossRef] [PubMed]

40. Shimizu, T.; Fujiwara, Y.; Osawa, T.; Sakai, T.; Kubo, K.; Kubo, K.; Nishitoba, T.; Kimura, K.; Senga, T.; Murooka, H.; et al. Orally active anti-proliferation agents: Novel diphenylamine derivatives as FGF-R2 auto-phosphorylation inhibitors. Bioorg. Med. Chem. Lett. 2004, 14, 875-879. [CrossRef] [PubMed]

41. Catoen-Chackal, S.; Facompré, M.; Houssin, R.; Pommery, N.; Goossens, J.-F.; Colson, P.; Bailly, C.; Hénichart, J.-P.; Catoen-Chackal, S.; Facompre, M.; et al. DNA Binding To Guide the Development of Tetrahydroindeno[1,2-b]pyrido[4,3,2-de]quinoline Derivatives as Cytotoxic Agents. J. Med. Chem. 2004, 47, 3665-3673. [CrossRef] [PubMed] 
42. Gasparotto, V.; Castagliuolo, I.; Ferlin, M.G. 3-substituted 7-phenyl-pyrroloquinolinones show potent cytotoxic activity in human cancer cell lines. J. Med. Chem. 2007, 50, 5509-5513. [CrossRef] [PubMed]

43. Magedov, I.V.; Manpadi, M.; Ogasawara, M.A.; Dhawan, A.S.; Rogelj, S.; van slambrouck, S.; Steelant, W.F.A.; Evdokimov, N.M.; Uglinskii, P.Y.; Elias, E.M.; et al. Structural Simplification of Bioactive Natural Products with Multicomponent Synthesis. 2. Antiproliferative and Antitubulin Activities of Pyrano[3,2-c]pyridones and Pyrano[3,2-c]quinolones. J. Med. Chem. 2008, 51, 2561-2570. [CrossRef] [PubMed]

44. Tseng, C.-H.; Chen, Y.-L.; Hsu, C.-Y.; Chen, T.-C.; Cheng, C.-M.; Tso, H.-C.; Lu, Y.-J.; Tzeng, C.-C. Synthesis and antiproliferative evaluation of 3-phenylquinolinylchalcone derivatives against non-small cell lung cancers and breast cancers. Eur. J. Med. Chem. 2013, 59, 274-282. [CrossRef] [PubMed]

45. Tseng, C.-H.; Chen, Y.-L.; Yang, C.-L.; Cheng, C.-M.; Han, C.-H.; Tzeng, C.-C. Synthesis of 6-substituted-9-methoxy-11H-indeno[1,2-c]quinoline-11-one derivatives as potential anticancer agents. Bioorg. Med. Chem. 2012, 20, 4397-4404. [CrossRef] [PubMed]

46. Santosa, R.C.; Salvadora, J.A.R.; Cortésb, R.; Pachónd, G.; Marinb, S.; Cascanteb, M. New betulinic acid derivatives induce potent and selective antiproliferative activity through cell cycle arrest at the $S$ phase and caspase dependent apoptosis in human cancer cells. Biochimie 2011, 93, 1065-1075. [CrossRef] [PubMed]

47. Szumilak, M.; Szulawska-Mroczek, A.; Koprowska, K.; Stasiak, M.; Lewgowd, W.; Stanczak, A.; Czyz, M. Synthesis and in vitro biological evaluation of new polyamine conjugates as potential anticancer drugs. Eur. J. Med. Chem. 2010, 45, 5744-5751. [CrossRef] [PubMed]

48. Tseng, C.-H.; Chen, Y.-L.; Lu, P.-J.; Yang, C.-N.; Tzeng, C.-C. Synthesis and antiproliferative evaluation of certain indeno[1,2-c]quinoline derivatives. Bioorg. Med. Chem. 2008, 16, 3153-3162. [CrossRef] [PubMed]

49. Li, S.-Y.; Chen, Y.-L.; Wang, C.; Tzeng, C.-C. Synthesis and antiproliferative evaluation of certain pyrido[3,2-g]quinoline derivatives. Bioorg. Med. Chem. 2006, 14, 7370-7376. [CrossRef] [PubMed]

50. Zhou, Q.; Melkoumian, Z.K.; Lucktong, A.; Moniwa, M.; Davie, J.R.; Strobl, J.S. Rapid induction of histone hyperacetylation and cellular differentiation in human breast tumor cell lines following degradation of histone deacetylase-1. J. Biol. Chem. 2000, 275, 35256-35263. [CrossRef] [PubMed]

51. Hengst, L.; Reed, S.I. Inhibitors of the Cip/Kip family. Curr. Top. Microbiol. Immunol. 1998, $227,25-41$. [PubMed]

52. Sherr, C.J.; Roberts, J.M. CDK inhibitors: positive and negative regulators of $\mathrm{G}_{1}$-phase progression. Genes Dev. 1999, 13, 1501-1512. [CrossRef] [PubMed]

53. Slingerland, J.; Pagano, M. Regulation of the Cdk inhibitor $\mathrm{p} 27$ and its deregulation in cancer. J. Cell. Physiol. 2000, 183, 10-17. [CrossRef]

54. Chu, I.M.; Hengst, L.; Slingerland, J.M. The Cdk inhibitor p27 in human cancer: Prognostic potential and relevance to anticancer therapy. Nat. Rev. Cancer 2008, 8, 253-267. [CrossRef] [PubMed]

55. Catzavelos, C.; Bhattacharya, N.; Ung, Y.C.; Wilson, J.A.; Roncari, L.; Sandhu, C.; Shaw, P.; Yeger, H.; Morava-Protzner, I.; Kapusta, L.; et al. Decreased levels of the cell-cycle inhibitor p27 ${ }^{\text {Kip1 }}$ protein: prognostic implications in primary breast cancer. Nat. Med. 1997, 3, 227-230. [CrossRef] [PubMed]

56. Esposito, V.; Baldi, A.; de Luca, A.; Groger, A.M.; Loda, M.; Giordano, G.G.; Caputi, M.; Baldi, F.; Pagano, M.; Giordano, A. Prognostic role of the cyclin-dependent kinase inhibitor p27 in non-small cell lung cancer. Cancer Res. 1997, 57, 3381-3385. [PubMed]

57. Loda, M.; Cukor, B.; Tam, S.W.; Lavin, P.; Fiorentinc, M.; Draetta, G.F.; Jessup, J.M.; Pagano, M. Increased proteasome-dependent degradation of the cyclin-dependent kinase inhibitor p27 in aggressive colorectal carcinomas. Nat. Med. 1997, 3, 231-234. [CrossRef] [PubMed]

58. Masciullo, V.; Sgambato, A.; Pacilio, C.; Pucci, B.; Ferrandina, G.; Palazzo, J.; Carbone, A.; Cittadini, A.; Mancuso, S.; Scambia, G.; et al. Frequent loss of expression of the cyclin-dependent kinase inhibitor p27 in epithelial ovarian cancer. Cancer Res. 1999, 59, 3790-3794. [PubMed]

59. Porter, P.L.; Barlow, W.E.; Yeh, I.-T.; Lin, M.G.; Yuan, X.P.; Donato, E.; Sledge, G.W.; Shapiro, C.L.; Ingle, J.N.; Haskell, C.M.; et al. p27 ${ }^{\text {Kip1 }}$ and cyclin $E$ expression and breast cancer survival after treatment with adjuvant chemotherapy. J. Natl. Cancer Inst. 2006, 98, 1723-1731. [CrossRef] [PubMed]

60. Tsihlias, J.; Kapusta, L.R.; DeBoer, G.; Morava-Protzner, I.; Zbieranowski, I.; Bhattacharya, N.; Catzavelos, G.C.; Klotz, L.H.; Slingerland, J.M. Loss of cyclin-dependent kinase inhibitor p27Kip1 is a novel prognostic factor in localized human prostate adenocarcinoma. Cancer Res. 1998, 58, 542-548. [PubMed] 
61. Barata, J.T.; Cardoso, A.A.; Nadler, L.M.; Boussiotis, V.A. Interleukin-7 promotes survival and cell cycle progression of T-cell acute lymphoblastic leukemia cells by down-regulating the cyclin-dependent kinase inhibitor p27(kip1). Blood 2001, 98, 1524-1531. [CrossRef] [PubMed]

62. Harada, K.; Hoque, M. O.; Bando, T.; Yoshida, H.; Sato, M. Over expression of p27 ${ }^{\text {Kip1 }}$ induces growth arrest and apoptosis in an oral cancer cell line. Oral Oncol. 2002, 38, 730-736.

63. Jia, W.; Liu, Y.; Li, W.; Liu, Y.; Zhang, D.; Zhang, P.; Gong, P. Synthesis and in vitro anti-hepatitis B virus activity of $6 H$-[1] benzothiopyrano[4,3-b] quinolin-9-ols. Bioorg. Med. Chem. 2009, 17, 4569-4574. [CrossRef] [PubMed]

64. Meth-Cohn, O.; Narine, B.; Tarnowski, B. A versatile new synthesis of quinolines and related fused pyridines, Part 5. The synthesis of 2-chloroquinoline-3-carbaldehydes. J. Chem. Soc. Perkin. Trans. 1 1981, 1, 1520-1530. [CrossRef]

65. French, H.E.; Wirtel, A.F. Alpha-naphthylisocynate as a regaent for phenols and aliphatic amines. J. Am. Chem. Soc. 1926, 48, 1736-1739. [CrossRef]

66. Gligorijević, N.; Todorović, T.; Radulović, S.; Sladić, D.; Filipović, N.; Gođevac, D.; Jeremić, D.; Anđelković, K. Synthesis and characterization of new $\mathrm{Pt}(\mathrm{II})$ and $\mathrm{Pd}(\mathrm{II})$ complexes with 2-quinolinecarboxaldehyde seleno-semicarbazone: Cytotoxic activity evaluation of $\mathrm{Cd}(\mathrm{II}), \mathrm{Zn}(\mathrm{II}), \mathrm{Ni}(\mathrm{II}), \mathrm{Pt}(\mathrm{II})$ and $\mathrm{Pd}(\mathrm{II})$ complexes with heteroaromatic. Eur. J. Med. Chem. 2009, 44, 1623-1629. [CrossRef] [PubMed]

67. Ramachandran, E.; Thomas, S.P.; Poornima, P.; Kalaivani, P.; Prabhakaran, R.; Padma, V.V.; Natarajan, K. Evaluation of DNA binding, antioxidant and cytotoxic activity of mononuclear Co(III) complexes of 2-oxo-1,2-dihydrobenzo[H]quinoline-3-carbaldehyde thiosemicarbazones. Eur. J. Med. Chem. 2012, 50, 405-415. [CrossRef] [PubMed]

68. Serda, M.; Kalinowski, D.S.; Mrozek-Wilczkiewicz, A.; Musiol, R.; Szurko, A.; Ratuszna, A.; Pantarat, N.; Kovacevic, Z.; Merlot, A.M.; Richardson, D.R.; et al. Synthesis and characterization of quinoline-based thiosemicarbazones and correlation of cellular iron-binding efficacy to anti-tumor efficacy. Bioorg. Med. Chem. Lett. 2012, 22, 5527-5531. [CrossRef] [PubMed]

69. CCDC 1436247 contains the supplementary crystallographic data for this paper. These data can be obtained free of charge via http:/ / www.ccdc.cam.ac.uk/conts/retrieving.html (or from the CCDC, 12 Union Road, Cambridge CB2 1EZ, UK; Fax: +44 1223 336033; E-mail: deposit@ccdc.cam.ac.uk)

70. Cheung, B.; Yan, J.; Smith, S.A.; Nguyen, T.; Lee, M.; Kavallaris, M.; Norris, M.D.; Haber, M.; Marshall, G.M. Growth inhibitory retinoid effects after recruitment of retinoid $X$ receptor $\beta$ to the retinoic acid receptor $\beta$ promoter. Int. J. Cancer 2003, 105, 856-867. [CrossRef] [PubMed]

71. Lai, S.M.F.; Orchison, J.J.A.; Whiting, D.A. A new synthetic approach to the rotenoid ring system. Tetrahedron 1989, 45, 5895-5906. [CrossRef]

72. Hardouin, C.; Kelso, M.J.; Romero, F.A.; Rayl, T.J.; Leung, D.; Hwang, I.; Cravatt, B.F.; Boger, D.L. Structure-activity relationships of alpha-ketooxazole inhibitors of fatty acid amide hydrolase. J. Med. Chem. 2007, 50, 3359-3368. [CrossRef] [PubMed]

73. Harvill, E.K.; Herbst, R.M.; Schreiner, E.C.; Roberts, C.W. The Synthesis of 1,5-disubstituted tetrazoles. J. Org. Chem. 1950, 15, 662-670. [CrossRef]

74. Ecke, G.G.; Napolitano, J.P.; Kolka, A.J. The ortho-alkylation of aromatic amines. J. Org. Chem. 1956, 21, 711-712. [CrossRef]

75. Horning, E.C.; Horning, M.G. Aromatization Studies. V. Synthesis of alkylanilines from alkylcyclohexenones. J. Am. Chem. Soc. 1947, 69, 1907-1908. [CrossRef]

76. Shvo, Y.; Arisha, A.H.I. Regioselective Catalytic dehydrogenation of aldehydes and ketones. J. Org. Chem. 1998, 63, 5640-5642. [CrossRef]

77. Prakash Naik, H.R.; Bhojya Naik, H.S.; Ravikumar Naik, T.R.; Raghavendra, M.; Aravinda, T.; Lamani, D.S. Synthesis of quinoline-based thieno-seleno-phenylquinazolinones. Phosphorus Sulfur. 2009, 184, 460-470. [CrossRef]

78. Doboszewski, B.; Herdewijn, P. Carbohydrate chiral-pool approach to four enantiomerically pure 2-naphthylmethyl 3-hydroxy-2-methylbutanoates. Tetrahedron 2008, 64, 5551-5562. [CrossRef]

79. El-Rayyes, N.R.; Katrib, A.H. Synthesis and Xray photoelectron spectra of some azines. J. Chem. Eng. Data 1983, 28, 132-134. [CrossRef]

80. Forbes, E.J.; Stacey, M.; Tatlow, J.C.; Wragg, R.T. The synthesis of 1-, 2- and 3-trifluoromethylcarbazoles by the fischer-indole method. Tetrahedron 1960, 8, 67-72. [CrossRef] 
81. Marshall, G.M.; Bell, J.L.; Koach, J.; Tan, O.; Kim, P.; Malyukova, A.; Thomas, W.; Sekyere, E.O.; Liu, T.; Cunningham, A.M.; et al. TRIM16 acts as a tumour suppressor by inhibitory effects on cytoplasmic vimentin and nuclear E2F1 in neuroblastoma cells. Oncogene 2010, 29, 6172-6183. [CrossRef] [PubMed]

Sample Availability: Samples of the compounds 14, 15, 16, 17, 18, 19, 26, 27 and 28 are available from the authors.

(C) 2016 by the authors; licensee MDPI, Basel, Switzerland. This article is an open access article distributed under the terms and conditions of the Creative Commons Attribution (CC-BY) license (http:/ / creativecommons.org/licenses/by/4.0/). 